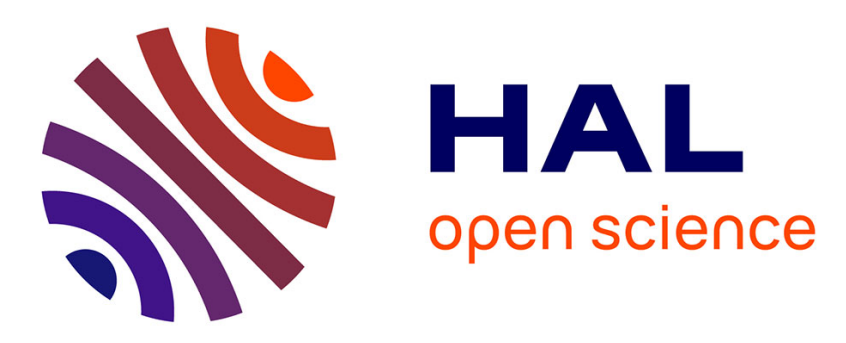

\title{
eXtended Reality for Cultural Heritage
}

Ronan Gaugne, Jean-Baptiste Barreau, Flavien Lécuyer, Théophane Nicolas, Jean-Marie Normand, Valérie Gouranton

\section{To cite this version:}

Ronan Gaugne, Jean-Baptiste Barreau, Flavien Lécuyer, Théophane Nicolas, Jean-Marie Normand, et al.. eXtended Reality for Cultural Heritage. Handbook of Cultural Heritage Analysis, pp.1405 1437, 2022, 10.1007/978-3-030-60016-7_48 . hal-03548338

\section{HAL Id: hal-03548338 \\ https://inria.hal.science/hal-03548338}

Submitted on 31 Jan 2022

HAL is a multi-disciplinary open access archive for the deposit and dissemination of scientific research documents, whether they are published or not. The documents may come from teaching and research institutions in France or abroad, or from public or private research centers.
L'archive ouverte pluridisciplinaire HAL, est destinée au dépôt et à la diffusion de documents scientifiques de niveau recherche, publiés ou non, émanant des établissements d'enseignement et de recherche français ou étrangers, des laboratoires publics ou privés. 


\title{
eXtended Reality for Cultural Heritage
}

\author{
Ronan Gaugne, Jean-Baptiste Barreau, Flavien Lécuyer, \\ Théophane Nicolas, Jean-Marie Normand, and Valérie Gouranton
}

R. Gaugne ( $\square)$

Univ Rennes, Inria, CNRS, IRISA, Rennes, France

e-mail: ronan.gaugne@irisa.fr

J.-B. Barreau

CNRS, Université Paris 1 Panthéon-Sorbonne, Paris, France

e-mail: jean-baptiste.barreau@cnrs.fr

F. Lécuyer $\cdot$ V. Gouranton $(\bowtie)$

Univ Rennes, INSA Rennes, Inria, CNRS, IRISA, Rennes, France

e-mail: flavien.lecuyer@irisa.fr; valerie.gouranton@irisa.fr

T. Nicolas $(\bowtie)$

Inrap, UMR 8215 Trajectoires, Rennes, France

e-mail: theophane.nicolas@inrap.fr

J.-M. Normand

Ecole Centrale de Nantes, AAU UMR 1563, Nantes, France

e-mail: jean-marie.normand@ec-nantes.fr 
48.6.4 Annotation of Megalithic Art with Augmented Reality ............. 1430

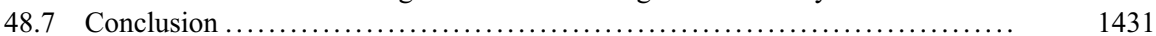

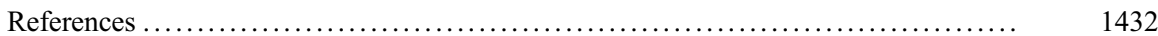

\section{Abstract}

3D data production techniques, although increasingly used by archaeologists and Cultural Heritage practitioners, are most often limited to the production of $2 \mathrm{D}$ or $3 \mathrm{D}$ images. Beyond the modes of visualization of these data, it is necessary to wonder about their possible interactions and uses. Virtual Reality, Augmented Reality, and Mixed Reality, collectively known as eXtended Reality, XR, or Cross Reality, make it possible to envisage natural and/or complex interactions with 3D digital environments. These are physical, tangible, or haptic (i.e., with effort feedback) interactions, which can be understood through different modalities or metaphors, associated with procedures or gestures. These interactions can be integrated by archaeologists in the "operating chain" of an operation (from the ground to the study phase), or be part of a functional reconstitution of the procedures and gestures of the past, in order to help understand an object, a site, or even a human activity. The different case studies presented in this chapter result from collaborations between archaeologists, historians, and computer scientists. They illustrate different interactions in 3D environments, whether they are operational (support for excavation processes) or functional (archaeological objects, human activities of the past).

\subsection{Introduction to eXtended Reality}

eXtended Reality (XR) is generally presented as an encompassing concept that integrates technological platforms, 3D digital content, as well as the user experience to view and interact with digital and/or physical objects in a real and/or digital environment. XR can also be seen as a generic term that includes Virtual Reality (VR), Augmented Reality (AR), and Mixed Reality (MR), the latter being generally seen as a generalization of both VR and AR (see Fig. 48.1).

Virtual reality is often considered solely as a field of computer science in relation to interactive digital 3D worlds. It actually holds a special position in the usual scientific scheme by coupling humanities sciences with engineering. According to Fuchs et al. [2] "The purpose of virtual reality is to allow a sensorimotor and cognitive activity for a person (or persons) in a digitally created artificial world, which can be imaginary, symbolic or a simulation of certain aspects of the real

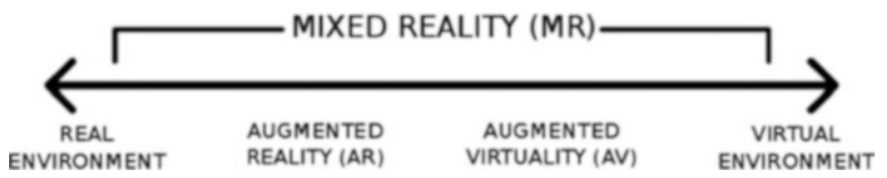

Fig. 48.1 The Milgram continuum [1] 
world." This assertion positions the user and his/her activity at the center of VR. The user is immersed through his/her mind, senses, and body.

Immersion is the "state (perceptual, mental, emotional) of a subject when one or more senses are isolated from the outside world and are fed solely by information from the computer" [3]. For mixed reality applications, immersion can be an important factor, as it allows the user to focus more on the artificial content displayed.

Related to VR, Augmented Reality is a domain of applications that combines the real and the virtual, in real time, and gives the appearance that virtual and real objects "coexist in the same three-dimensional world" [4]. AR increases the visualization of reality with digital data and allows the user to interact with both environments (real and/or digital).

For both virtual and augmented reality, the environment needs to be reactive, in order to change according to the user's actions. To make it possible, Mixed Reality applications need to be real-time, i.e., that actions of the user need to be taken into account and transformed into actions on the digital content without the user being able to notice any delay.

These different areas of Mixed Reality are presented in the Milgram continuum [1] (Fig. 48.1) in which one starts from real environments from one end of the continuum and go to pure Virtual Environments (VE) at the other end, while passing through Augmented Reality.

As this is a continuum, many modalities co-exist in it. For instance, VR can be more or less immersive, depending on the kind of device used: a Head-Mounted Display (HMD) will enclose the user more strongly in the VE, making it farther on the VR side of the continuum than, for instance, a single screen. The different modalities existing in the spectrum of MR each have their own advantages and drawbacks, making each of them more or less adapted depending on the application.

\section{2 eXtended Reality for Cultural Heritage}

In archaeology, scientific processes based on VR, MR, or AR have known a tremendous increase in recent years. Virtual archaeology was first introduced by Reilly in 1990 [5] and was initially presented for excavation recording and virtual reexcavation using multimedia technologies. In a similar way, Krasniewicz, in 2000 , proposed a $360^{\circ}$ visualization infrastructure to help archaeologists in their research work [6]. In this case, virtual archaeology was not used to restore knowledge, but to acquire new knowledge.

In her works, Pujol-Tost also discussed the importance of the chosen representation for the 3D models in everywhere [7]. According to new trends in the domain, Forte [8], one of the mainstays of virtual archaeology, suggests to replace the terminology related to a "reconstitution of the past," by the expression "Cyber Archaeology" relying on a "simulation of the past." The distinction between "cyber archaeology" and "virtual archaeology" is justified by the extensive use of the term "virtual archaeology" for applications dedicated to visualization purposes. Hence, "cyber archaeology" makes the archaeologist more active in the process. 
Christou et al. [9] used an immersive CAVE-like structure combined with haptic devices and 3D sound for pedagogic purposes in a museum exhibition, but also as a tool for research. The Archave project [10] integrated also a CAVE-like structure and proposed tools for archaeologists to study historical sites. Another interesting work [11] presents a tool where archaeologists collaborate remotely on shared virtual objects through realistic avatars reconstructed from 3D cameras. Their virtual reality framework proposed a rich toolkit of interaction features, including navigation, measurement, lighting, and dragging. However, due to real-time 3D capture and rendering of users, the visualization was restricted to small image resolution $(320 \times 240$ pixels $)$ to ensure fluid rendering (25 FPS).

$\mathrm{XR}$ is widely used for Cultural Heritage valorization but remains seldom used for scientific purposes. We believe that fields of XR and Cultural Heritage may enjoy mutual benefits triggered by questions such as:

1. How can XR, considered in its whole scope from science and technology to human sciences and natural sciences, benefit the study of Cultural Heritage?

2. What are the specific challenges brought by Cultural Heritage?

Elements of reciprocal challenges are presented in Fig. 48.2. They are centered on three key notions: perception, interaction, and collaboration. Indeed, it is crucial to determine the relevant perception Cultural Heritage experts have of their environment and material of study, and to propose adapted modalities of perception in XR, taking into account the specificity of this particular family of users. To this aim, we have to identify the operational processes existing in the Cultural Heritage domain, in term of analysis, treatment, or conservation, to improve these processes and to imagine new processes based on XR. In the same way, it is also fundamental to understand interaction needs required by Cultural Heritage experts, to identify the contexts of interaction to consider, and to determine the purposes of interaction. Obviously, 1:1 interaction is important, but it may also be interesting to consider different scales of interaction, and even multi-scale. For example, in the case of an excavation site, it is required to manage the scale of the whole site that can be very

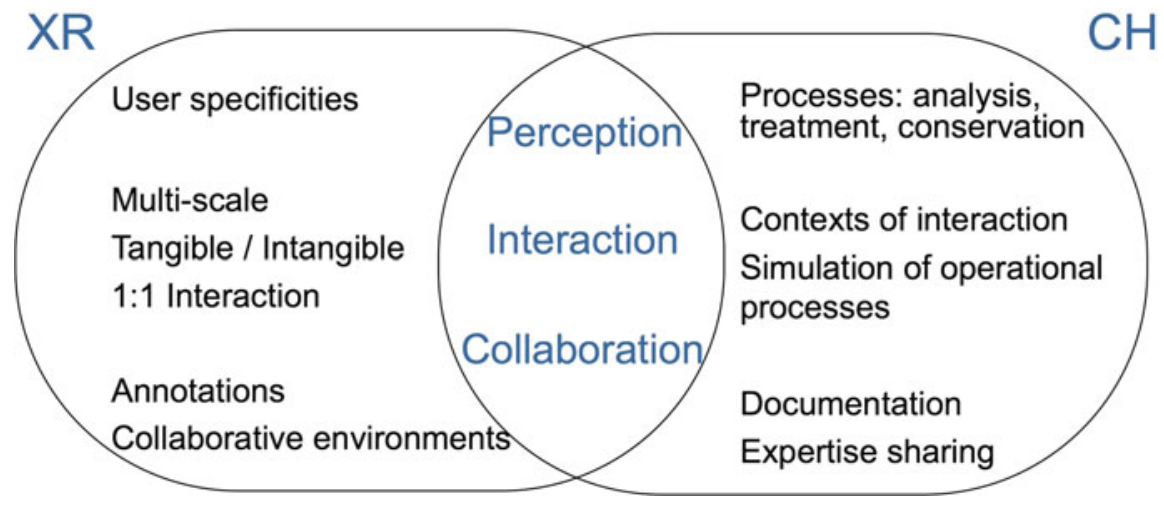

Fig. 48.2 Reciprocal challenges between $\mathrm{XR}$ and $\mathrm{CH}$ 
large and the scale of artifacts discovered on the site. Depending of the context, both tangible and intangible interactions must be considered, for example, to enable a physical interaction with an artifact [12], or to represent human activities in a context of intangible heritage [13]. Finally, Cultural Heritage experts need to collaborate and share their knowledge, which is related to collaborative virtual environments [8] and environment enrichment with annotations [14].

Immersion, particularly in 1:1 virtual environments (i.e., virtual environments represented at their real scale), allows Cultural Heritage experts such as archaeologists and historians to evaluate symbolic or cultural roles of architectural buildings. Moreover, Cultural Heritage experts can be placed in situations to validate specific activities, ranging from displacements within environments to more complex interactions by using haptic devices to evaluate the physical feasibility or the coherency of a task. This aspect strongly pertains to ergonomics and musculoskeletal activities, which are widely developed in the context of XR, especially in VR. As part of a scientific process, historical reconstitution in XR should aim at providing a meaningful environment for Cultural Heritage experts, which corresponds to the following scientific problems:

- Is the representation of the historical universe credible for Cultural Heritage experts? Realism and objective credibility are diametrically opposed issues. Objective credibility is an intrinsic quality of the reconstitution depending on the expert's perception. Just as an X-ray picture has functional credibility for a medical practitioner, virtual Cultural Heritage experts' models and environments must be designed to ensure this credibility. As Hermon and Nikodem developed [15], 3D modeling can only be used for archaeology under the conditions of data transparency and evaluability of the reconstruction's accuracy.

- Are Cultural Heritage experts able to evaluate hypotheses in the virtual reconstitution? Beyond the credibility of the reconstitution, the ability of an expert to acquire new knowledge in an XR context is a key concern of a scientific approach.

In order to allow Cultural Heritage experts to understand the functionalities of living spaces, social activities, as well as interactions, an XR simulation dedicated to heritage must have the capacity to (i) set the historical universe in a functional condition and (ii) put Cultural Heritage experts in situations to evaluate populations' actions and interactions. These two issues combine consistency of the reconstitution with credibility of the simulation.

\subsection{General Methodology}

We propose a scientific approach articulated around three cross-functional axes of use: (i) See, (ii) Manipulate, and (iii) Share related to the three challenge families presented above. These three axes correspond respectively to the challenges (i) Perception, (ii) Interaction, and (iii) Collaboration. The three axes are described in the following sections. 


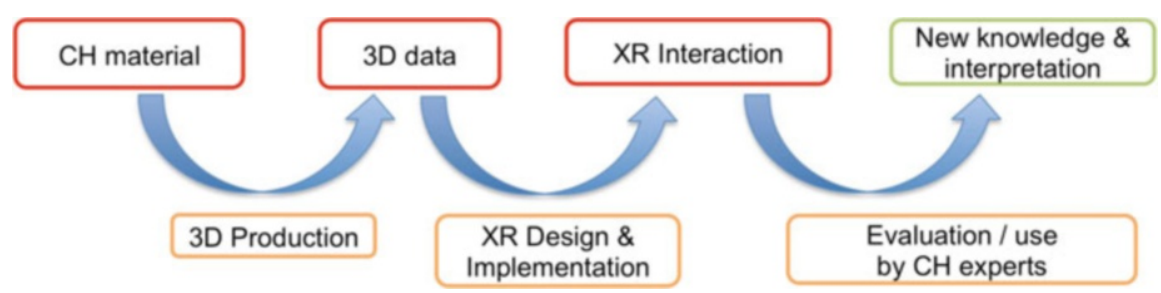

Fig. 48.3 Overview of the general methodology

All the axes follow the same general methodology starting from Cultural Heritage material and aiming at innovative usages for Cultural Heritage experts. Figure 48.3 presents the different steps of the process.

In this methodology, starting from Cultural Heritage that can be artifacts, monuments, excavation sites, or even written documents, paintings, sketches, etc., the first step consists in producing $3 \mathrm{D}$ data, either with $3 \mathrm{D}$ modeling or by digitization. In this last case, intermediate digital data can be produced, such as photos in photogrammetry, or Dicom data in CT scan, that must be processed to generate 3D data.

Many Cultural Heritage projects do not go beyond this step in their usage of 3D data. Even if this can be legitimate in case of illustration or scientific mediation, we prefer to consider these data as an intermediate step on which it is possible to design and product XR content and environments that can be used or evaluated by Cultural Heritage experts. We will present several instances of this methodology to illustrate different context of use or evaluation.

\subsection{1 "See" Axis Overview}

The "See" axis deals with the visualization of both the external and internal structures of archaeological material and its context. The problem here consists in identifying or designing production processes for the data to be visualized as well as modalities for visualizing these data. The production of data relies here on surface digitization technologies such as photogrammetry or laser scanning, as well as on 3D modeling, but also on internal composition detection, mainly using medical image techniques such as CT scan and Magnetic Resonance Imagery (MRI).

The viewing modes in an XR environment are based on the properties of the camera that displays the $3 \mathrm{D}$ world view. Interacting with this camera allows to navigate the $3 \mathrm{D}$ world. In the case of an XR environment, the camera generally corresponds to the point of view of the user, and thus is attached to the position of the user's head.

\subsection{2 "Manipulate" Axis Overview}

This axis deals with the interaction between the user and the object, whether this interaction is purely virtual or tangible. The goal here is to propose new interaction 
metaphors, based on XR methods and tools. It is important that these interactions are as natural as possible so that the technology fades behind the use and that they integrate into the operational processes of Cultural Heritage experts.

\subsection{3 "Share" Axis Overview}

This axis covers the documentation, sharing, and archiving of digital data. Its objective is twofold: (i) to work on the enrichment of the object at the digital level, by the integration of metadata associated with $3 \mathrm{D}$ data and/or the addition of spatialized information within 3D data, and (ii) to allow the researcher to crossreference information on digital corpora. This information can be shared through collaborative or successive work sessions, locally or remotely.

\subsection{D Production}

Producing 3D environments with and for Cultural Heritage involves a methodological decomposition that can be adapted to the broad range of issues raised by professionals in this community and the general public. By taking the temporal dimension as the linchpin and scientific knowledge as a driving force, the existing of a Cultural Heritage item can first be digitized, then virtually restored, as it was potentially, at such-and-such time. Figure 48.4 presents the different steps of the process of 3D production, mainly based on two approaches, (i) digitization that relies to the production of $3 \mathrm{D}$ data from real material and (ii) graphical design that corresponds to the production of $3 \mathrm{D}$ data by $3 \mathrm{D}$ modeling.

Fig. 48.4 3D production methodology

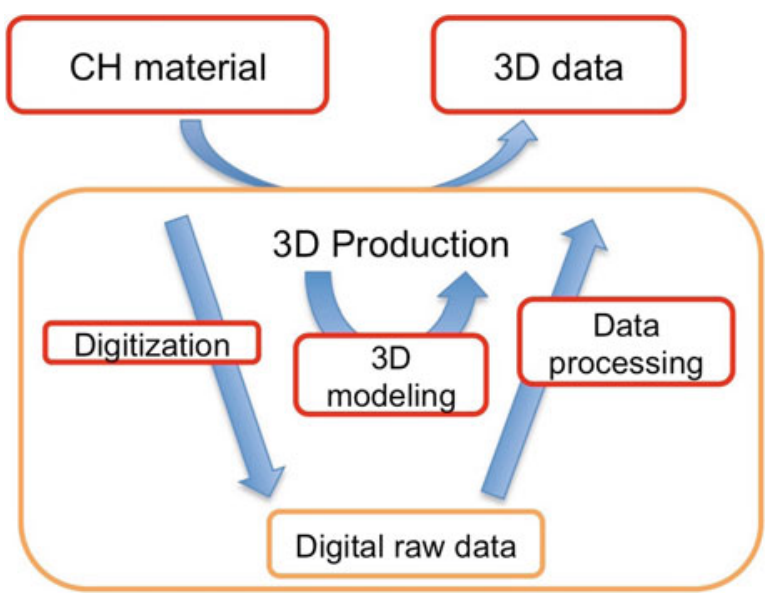




\subsubsection{Digitization and Data Processing}

In this section, we present several methods to digitize Cultural Heritage material, ranging from simple objects to the complete archaeological site, based on different technologies, with a specific focus on CT scan.

Photogrammetry Albrecht Meydenbauer (1834-1921) defined photogrammetry as the science (or technique) that provides reliable information about natural space or physical objects through the recording, measurement, and interpretation of photographs or produced by electromagnetic radiation or other phenomena [16]. More recent and coming directly from photogrammetry, Structure from Motion (SfM) is an imaging technique for estimating 3D structures from 2D image sequences [17]. This technology is still widely used in $\mathrm{CH}$ domain thanks to its ease of access and use; see, e.g., [18-22].

3D cameras, such as the Microsoft Kinect, motion sensing input devices, that can produce depth maps (images in which each pixel contains the distance between the camera and the nearest object) on top of 2D images. Such cameras can produce depth maps by different means (e.g., using Time-of-flight sensors), at different speed and resolutions. Such device provides a great advantage over classical 2D cameras when integrated into a SfM pipeline; see, e.g., [23-25].

An Unmanned Aerial Vehicle (UAV) is an aircraft, without a human pilot aboard, that can collect low-altitude aerial imagery [26-28].

Reflectance Transformation Imaging (RTI) allows to produce a dynamic image from a series of photographs under different artificial lighting [29]. This technology is particularly convenient for the digitization of thin reliefs such as handwriting traces or engraves; see, e.g., [30-32].

3D scanning is a surveying method performed by a laser scan that allows to obtain 3D coordinates of visible surface points in a fast, contactless, and automatic way. Current laser scanners use different methods of distance measurement [33]. This technology provides precise 3D recording of $\mathrm{CH}$ material at various scales [34-38].

Computed tomography (CT) and $\boldsymbol{\mu}$-tomography are X-Ray-based techniques allowing, in particular, the study of the interior of $\mathrm{CH}$ items [39]. These techniques make it possible to reconstruct an object volume from a series of measurements made by slices from outside this object. The $\mu$-tomography allows to work on a small scale, ranging from sub-millimeters to a few centimeters, and with a spatial resolution of a few microns. These different techniques are more and more used for a wide range of $\mathrm{CH}$ material [40-44].

\section{CT Scan}

Computed tomography (CT) [45] is an imaging technology widely used in medicine; CT scanners use computer-processed X-rays to produce tomographic images (i.e., virtual "slices") of specific areas of the scanned object.

Data obtained during CT scan consist in a set of continuous attenuation profiles called a sinogram [46]. The sinogram is not directly usable and requires a mathematical processing, a double inverse Fourier transform, to obtain images on which a convolution filter is applied, low-pass filter or high-pass filter, to optimize either 

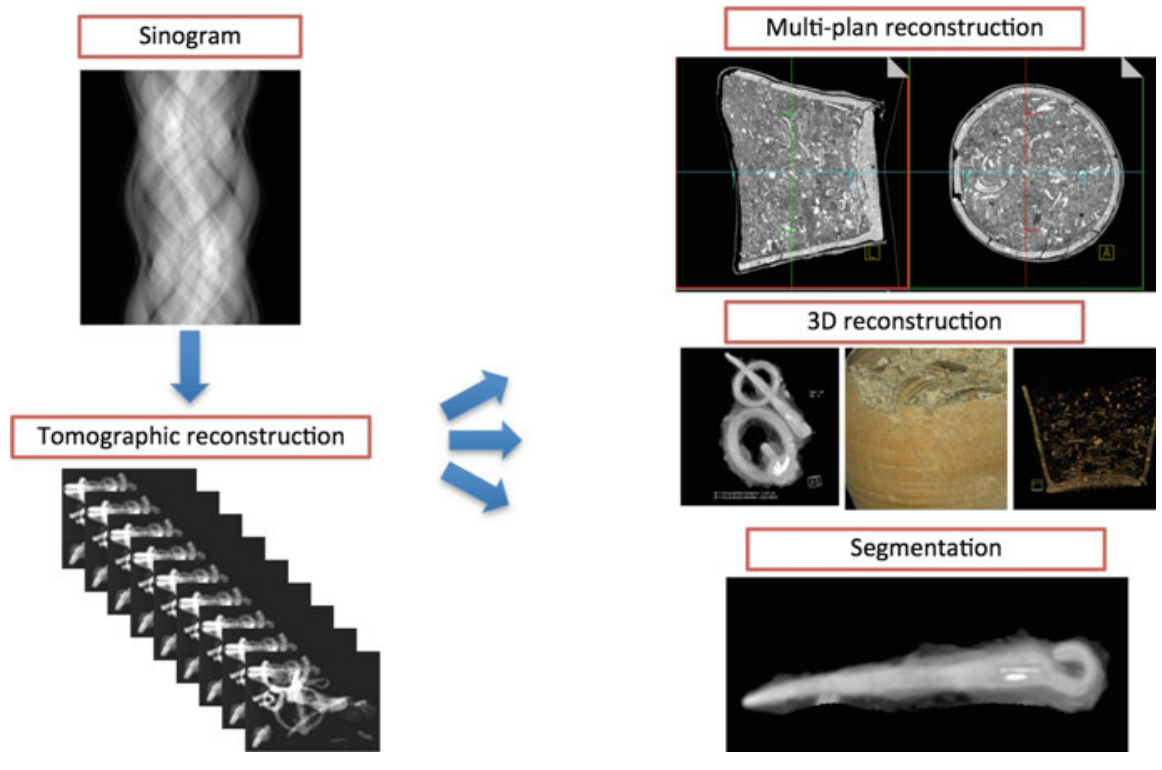

Fig. 48.5 Data processing with CT scan

density resolution or spatial resolution. The set of images obtained from this tomographic reconstruction (see Fig. 48.5) is used for 2D and 3D post-processing, such as multi-plan reconstruction, 3D reconstruction, and segmentation.

Multi-plan reconstruction: this post-processing, also known as 2D MPR, allows to define a new slicing of the initial object in a different plan than the one used during acquisition.

$3 \mathrm{D}$ reconstruction: this post-processing aims at highlighting, subsequently to the analysis of 2D images, relevant information in a clear and easy to understand way. The highlight of the different components of the material is based on density information calculated during the CT scan, called the radiodensity, and expressed relatively to the Hounsfield scale [47]. The resulting images are also named iconographic images.

Segmentation: this post-processing allows to isolate portions of the data in order to focus on relevant parts, and to remove noise data. This technique is particularly important to study nested artifacts.

\subsubsection{Graphical Design}

Distinguished from 3D digitization and more commonly referred to as "graphical design," 3D modeling of no-longer existing Heritage material leads to a much higher involvement of archaeologists in the sense that their knowledge is the raw material of the restitution process.

A large majority of archaeological restitution concerns and has concerned architecture, so we will focus on this kind of reconstitution. 
Robert Vergnieux synthesizes the heritage uses of 3D architectural restitutions in archaeology [48]. He explains the enthusiasm for them by the immediacy of the visual impact they generate, which greatly facilitates Cultural Heritage enhancement by feeding the collective imagination. Constrained by narrative and playfulness issues, these images, whose photorealism can sometimes freeze information in people's minds, can nevertheless convey uncertainties, false information, anachronisms, and approximations of details.

\section{Theoretical and Architectural Origins}

\section{Typology}

At the beginning of the nineteenth century, Jean-Nicolas-Louis Durand developed an analytical typology based on the plans by creating a catalogue of typological references and rules for architectural design [49]. These concern the built framework and its entire environment. Later other works were carried out on the urban scale [50]. The representation contributes to the typological analysis that brings together the essential properties of a category of real objects and makes it possible to report them sparingly.

\section{Representation Modes}

The "classical" objectives of the representation of built architecture are:

- Setting the object of study in its morphology and dimensions

- Objectively organizing the relationships between the different elements of the object of study

- Getting as full a description as possible with minimal means

There are several graphic representation techniques whose choice depends on many factors (size, level of detail, recipient's profession, practices, agreements, etc.). Among them, we find the geometrical, axonometric, and perspective drawings (cf. Table 48.1).

\section{Architectural Modeling}

\section{Styles}

Before discussing the types of restitutions, we can mention two models of archaeological restitution developed in the nineteenth century:

- Ruskin represents a "conservationist" point of view and advocates "non-intervention" on the remains [52].

- Viollet-le-Duc advocates the total reconstruction of the ruins: To restore a building is not to maintain, repair, or rebuild it, it is to restore it to a complete state that may never have existed at a given time [53]. 
These two trends have led to the existence of six modern restitution models presented in Table 48.2.

We can mention three types of geometric 3D models with an architectural vocation and based on surveys $[54,55]$ :

- As surveyed: It is the object as it exists at the time of the survey and its most accurate modeling.

Table 48.1 Techniques for the graphical representation of built architecture [51]

\begin{tabular}{l|l|l|l}
\hline & $\begin{array}{l}\text { Geometrical drawing: } \\
\text { plans, sections, and } \\
\text { elevations }\end{array}$ & Axonometric drawing & Perspective drawing \\
\hline Projection & $\begin{array}{l}\text { Orthogonal on at least } \\
\text { two planes }\end{array}$ & Orthogonal on one plane & $\begin{array}{l}\text { Conic from a given } \\
\text { point of view on a } \\
\text { plane }\end{array}$ \\
\hline $\begin{array}{l}\text { Representation } \\
\text { of the subject }\end{array}$ & $\begin{array}{l}\text { As it is in itself without } \\
\text { distortion of perspective }\end{array}$ & $\begin{array}{l}\text { As it would be seen by } \\
\text { an observer placed in } \\
\text { infinity }\end{array}$ & $\begin{array}{l}\text { As the observer sees } \\
\text { it in reality }\end{array}$ \\
\hline
\end{tabular}

Table 48.2 Modern restitution models

\begin{tabular}{|c|c|c|}
\hline $\begin{array}{l}\text { Restitution } \\
\text { model }\end{array}$ & Definition & Examples \\
\hline $\begin{array}{l}\text { Restitution of } \\
\text { the monument } \\
\text { on site }\end{array}$ & $\begin{array}{l}\text { Reconstitute the architecture or } \\
\text { monuments on the remains, using } \\
\text { the materials and techniques that } \\
\text { have been documented on the site, } \\
\text { in order to give the buildings an } \\
\text { appearance similar to that they had } \\
\text { at the time of the site's life }\end{array}$ & $\begin{array}{l}\text { Pompeii, Herculaneum, Martigues } \\
\text { (Bouches-du-Rhône, France), and } \\
\text { Augusta Raurica (Switzerland) }\end{array}$ \\
\hline $\begin{array}{l}\text { Restitution of } \\
\text { volumes }\end{array}$ & $\begin{array}{l}\text { Action executed on the remains, but } \\
\text { using materials clearly different } \\
\text { from those used on the site }\end{array}$ & $\begin{array}{l}\text { Piazza Armerina (Sicily) and } \\
\text { Xanten Thermae (Germany) }\end{array}$ \\
\hline Transfer model & $\begin{array}{l}\text { Moving a site or, more frequently, a } \\
\text { part of the site (one or more } \\
\text { buildings) to a different location } \\
\text { from the original one }\end{array}$ & $\begin{array}{l}\text { Skansen on the island of Djurgården } \\
\text { (Stockholm), Kolomenskoye Park } \\
\text { (Moscow), and Latenium } \\
\text { (Neuchâtel, Switzerland) }\end{array}$ \\
\hline Replica model & $\begin{array}{l}\text { Partial or complete restitution of a } \\
\text { site on a separate space-even far- } \\
\text { from the site, i.e., on a space where } \\
\text { there are no archaeological remains }\end{array}$ & Plymouth (Massachusetts) \\
\hline $\begin{array}{l}\text { Conservationist } \\
\text { model }\end{array}$ & $\begin{array}{l}\text { Minimal intervention, which is } \\
\text { normally limited to consolidation or } \\
\text { restoration of the remains }\end{array}$ & $\begin{array}{l}\text { Consolidation in most } \\
\text { archaeological sites in Europe }\end{array}$ \\
\hline Virtual model & $\begin{array}{l}\text { Show the restitution of the site } \\
\text { (or part of the site) without } \\
\text { physically materializing it, normally } \\
\text { using graphic means }\end{array}$ & $\begin{array}{l}\text { No-longer existing sites such as the } \\
\text { first Palais de l'Intendant in Québec, } \\
\text { or the Roman Theater in Fano, Italy }\end{array}$ \\
\hline
\end{tabular}


- As built: It is the object without any extrapolation. The model is used to mask the effect of stone erosion and minor defects due to time. The objective is to get the original state of the element detected.

- Reconstitution: The measurements are completed by the expertise of the specialist: archaeologists, architects, etc. They validate all the assumptions made during the modeling process to ensure that the model is complete.

The fundamental principle of any restitution is the guarantee of the conservation of the site or the remains [56]. There are several fields concerned by the restitution procedures: the scientific field of archaeology, education, tourism, and heritage presentation. In the following, we will only deal with aspects of production and scientific mediation.

Scientific production Whatever its model, the scientific interest of the restitution allows the verification of the hypotheses made about the old buildings [57]. For the virtual model, Robert Vergnieux indicated in 2011 that in the scientific context, the restitution process is complex, multidisciplinary, and requires years of research. The methodological objective of 3D models is to be able to raise all the validation questions involved in the restitution work. Unlike 3D models for illustration purposes, the idea is to include all the structural units of the buildings that make it up. The reader of the image must also be able to identify the uncertainties, the chronological phase(s) selected, the version, and the documentary sources. More recently, if respect and management of documentary sources seem to be applied [58], the way in which constraints, choices and points of view of restitution influence and alter the relationship to data and sources, raises questions [59].

\subsection{XR Design and Implementation for Cultural Heritage}

There are many technological possibilities to implement an XR application offering different experiences and interactions for the user [60-62]. In this section, we will present the main different systems and interactions that can be proposed, and we will develop two notions of interaction that can be used in a Cultural Heritage context. Figure 48.6 presents the different steps of the process of XR design and implementation in this context.

\subsubsection{XR Systems for Cultural Heritage}

In this section we briefly present the common technologies of XR. Since each type of $\mathrm{XR}$ system has its own characteristics and some might prove more suitable for certain use cases of $\mathrm{CH}$, we present a clear taxonomy of VR/AR technologies and present their advantages and limitations. 


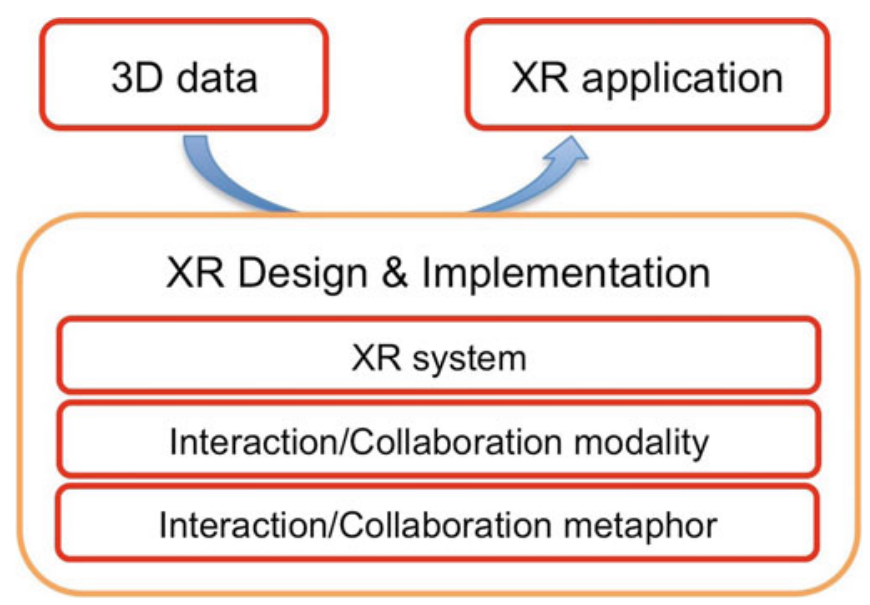

Fig. 48.6 Overview of the general methodology for XR design and implementation

\section{Virtual Reality Systems}

\begin{tabular}{|c|c|}
\hline CAVE & $\begin{array}{l}\text { [63] are high-end VR facilities comprising of multiple walls on which stereoscopic } \\
\text { 3D content can be projected in real-time. Users can interact at scale } 1 \text { with virtual } \\
\text { objects. Such systems are generally single-user even if some seldom facilities } \\
\text { propose multiple-users implementation. But in this last case, the system raises } \\
\text { occlusion issues between the user and the virtual scene. CAVE-like systems are } \\
\text { very comfortable for the user as he/she is present with his/her own body in the } \\
\text { simulation and can move naturally within the physical space [64-66]. The main } \\
\text { drawback of this kind of system is its cost }\end{array}$ \\
\hline Workbench & $\begin{array}{l}\text { This term is usually used to refer to a combination of one or more screens used to } \\
\text { display stereoscopic 3D content. Unlike Caves, workbenches do not necessarily } \\
\text { allow for a scale } 1 \text { interaction with virtual objects. However, their limited size and } \\
\text { cost make them an interesting system to provide interactions in a stereoscopic } \\
\text { environment. In particular, they can represent an efficient tool to work on limited } \\
\text { size objects such as the ones studied in archaeological laboratories [67] }\end{array}$ \\
\hline HMDs & $\begin{array}{l}\text { Head-Mounted Displays are headsets that can be used to display 3D stereoscopic } \\
\text { content. Users are occluded from the real world and are thus more immersed than } \\
\text { within a Cave or with a workbench. The main drawback of this kind of system is } \\
\text { that the user loses the relation with his/her own body, but HMDs have become very } \\
\text { popular thanks to their low price. They are widely used in Museum to provide } \\
\text { immersive experiences for the visitors }\end{array}$ \\
\hline
\end{tabular}

\section{Augmented Reality Systems}

VST $\quad$ Video see-through [1] AR are either "Hand Held" systems based on tablets or smartphones or "Head Mounted Displays" with cameras such as Windows Mixed Reality headsets. In this case, the real scene is filmed through the cameras of the device, and the digital content is then inserted to be displayed on the screen (or screens) of the VST 


\begin{tabular}{l|l}
\hline & $\begin{array}{l}\text { device. This kind of AR systems is very popular in Museum contexts as they just require a } \\
\text { smartphone or a simple tablet. Interactions and complexity of simulations proposed with } \\
\text { VST are limited by the computing performances of the device, and the display is } \\
\text { monoscopic. HMDs provide stereoscopic rendering, but the quality of the view of the real } \\
\text { world is dependent of the performance of the cameras of the device }\end{array}$ \\
\hline OST & $\begin{array}{l}\text { Optical see-through [1] AR are systems where the user sees reality directly through semi- } \\
\text { transparent screens in front of his/her eyes, which insert some digital content, like the } \\
\text { Microsoft HoloLens and the Magic Leap. This kind of system is increasingly used as it } \\
\text { provides a natural view of the real world with hand tracking for interactions. The current } \\
\text { versions of these devices are still perfectible in terms of field of view and tracking, but the } \\
\text { applications in CH are promising [68] }\end{array}$ \\
\hline SAR & $\begin{array}{l}\text { Spatial (or Spatially) Augmented Reality [69] is a term used in the AR community to } \\
\text { characterize projective AR where 3D digital content is directly projected on the reality, } \\
\text { i.e., onto real objects. This kind of system is widely used in cultural performances on } \\
\text { monuments but can also be used to project surface textures on Cultural Heritage objects } \\
\text { such as engraves or statues with particular calibration and deformation processes } \\
\text { [70, 71]. This kind of system can also be used to display the internal content of an object, } \\
\text { but in this case the system must deal with depth perception and integrate a head tracking } \\
\text { to display the correct user's point view [72] }\end{array}$ \\
\hline
\end{tabular}

\subsubsection{XR Interaction and Collaboration in Cultural Heritage}

In this section, we present general interaction concepts in XR, and the main kinds of interaction according to [73].

- Navigation: This interaction with user's point of view is fundamental as it is the main and often only interaction with the virtual universe. In this case, the user interacts with the camera related to his/her point of view.

- Interaction with virtual environment: This family of interactions is related to the modification of the characteristics of some objects that belong to the simulation of the virtual environment. We detail below this family of interaction that opens many interesting possibilities for Cultural Heritage domain to benefit from XR.

- Interaction with application: This family of interactions is related to the modification of the properties of the XR application through dialog objects that are not related to the simulation.

An interaction is defined by several characteristics. The first concerns the modality(ies), i.e., the means of the users that are implemented to effect the interaction (hand, body, gaze, brain). A second characteristic is the metaphor, i.e., a representation of the interaction in the virtual world to make it understandable to the user (virtual hand, pointer, radius, virtual tool). The last characteristic is the device used, i.e., a technical device used in the interaction. These different characteristics are widely documented in the literature to identify the most adapted and relevant ones according to a specific domain and specific task. 

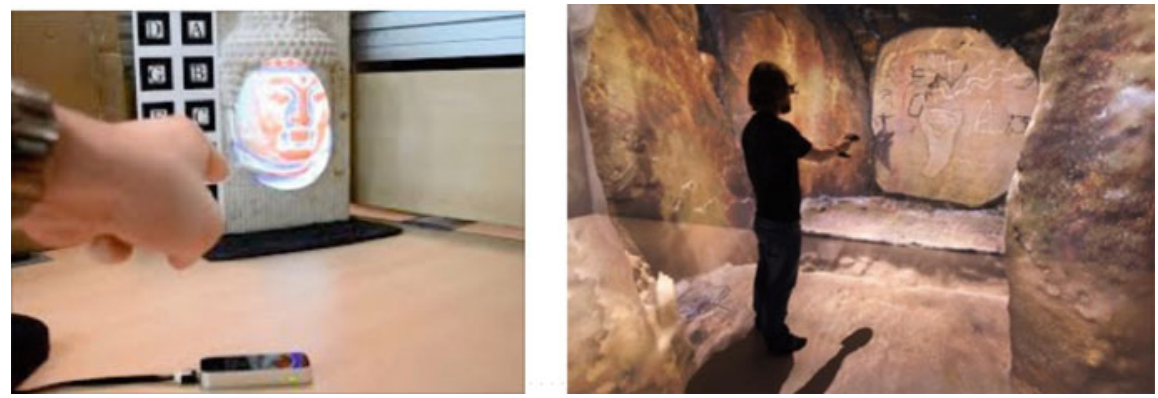

Fig. 48.7 Operational interactions with engraves in Augmented Reality (left) and Virtual Reality (right)

In Cultural Heritage applications, we propose to distinguish between two families of interactions with the virtual environment, (i) functional interactions that put in function objects, monuments, or sites and (ii) technical interactions, such as annotations, cutting plans, or taking measurements.

Functional interactions are associated to a simulation of the functioning of an archaeological context, be it a site, a building, or an object. They allow the user to put these artifacts into operation in the simulation. In the reconstitution of industrial heritage presented in [74], the user can interact with complex elements of an old power plant. In the example of the reconstitution of the eighteenth-century East India Company, Boullongne [75], the user can manipulate the ship's steering wheel and vary the navigation heading, or ring the quarter change bell. This kind of interaction is not unique to archaeology. In the medical field, the user can interact with surgical instruments and perform surgery [76-78], or in the industrial field the user can interact with complex machine tools simulated in Virtual Reality [79-81].

Operational interactions can act on the representation of an object, a building, or a site to generate study data or new representations as part of a business process. Thus, in [71], using a projective augmented reality system, stone etchings are augmented by a numerical representation in order to highlight the relief (Fig. 48.7 on the left). In a second example presented in [82], engravings in a room in Barnenez's cairn are highlighted in a virtual reality reconstruction, based on photogrammetric scanning (Fig. 48.7 on the right).

\section{Functional Interactions}

In the following, we present examples of functional interactions implemented in the framework of cases of archaeological studies carried out during different projects. These examples are intended to illustrate these cases of use of interactions in order to stimulate reflection on its interest in the archaeological operating chains.

\section{Functional Interaction with an Object: Ossé's Weight}

The granite weight of Ossé (La Claraiserie, Ille et Vilaine, France) was found in a farm dating from the second or first century before our era, in a deposit of metal 


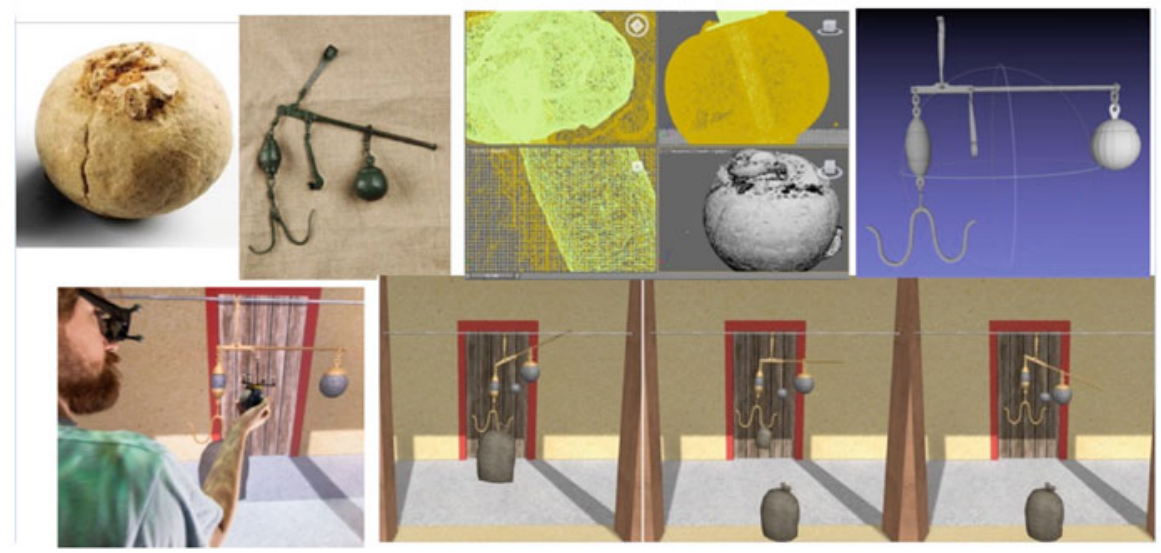

Fig. 48.8 Actual weight and steelyard (top, left), digitization and modeling (top, center, and right), and functional interaction in historical context, in Virtual Reality (bottom)

objects, as part of preventive excavations conducted by Inrap, the French National Institute for Preventive Archaeological Research. To better understand the use of this weight, we proposed in [12] a modeling of a roman steelyard, based on fragments found on the same site, and on a complete balance found on another similar site, and a reconstruction of the physical behavior, in a virtual environment representing a site of the same era; see Fig. 48.8. The user immersed in the virtual universe can then weigh objects and put back into operation this scale: he can catch bags with different sizes and hang them to the hook, and move the counterweight to balance the system and measure the weight of the bag. In addition, we used a copy of 3D print weight as a tangible object for interacting in virtual reality simulation. Thanks to an infra-red camera position capture system, this object is recognized and tracked in the environment, and the user can use this weight in interaction with the scale by weighing virtual objects.

\section{Functional Interaction with a Building: The Boullongne}

Boullongne, ship of the East India Company of the eighteenth century, was the subject of a special study by the department of Maritime History of the University South Brittany, because of the conservation of numerous documents such as logbooks, and naval architecture technical plans. To allow a better understanding of life on board, it was decided to build a virtual replica of this ship. The modeling was carried out by the West Digital Conservatory for Archaeological Heritage project [83] from the plans and a model of the ship. From this modeling, we put this vessel into operation by a physical simulation of the vessel and its environment as presented in [75].

We first worked on the waterline of the boat on a simulation of the water so that the ship moves according to the state of the sea. In a second step, we proposed interactions to the user so that the user can interact with the objects constituting the 


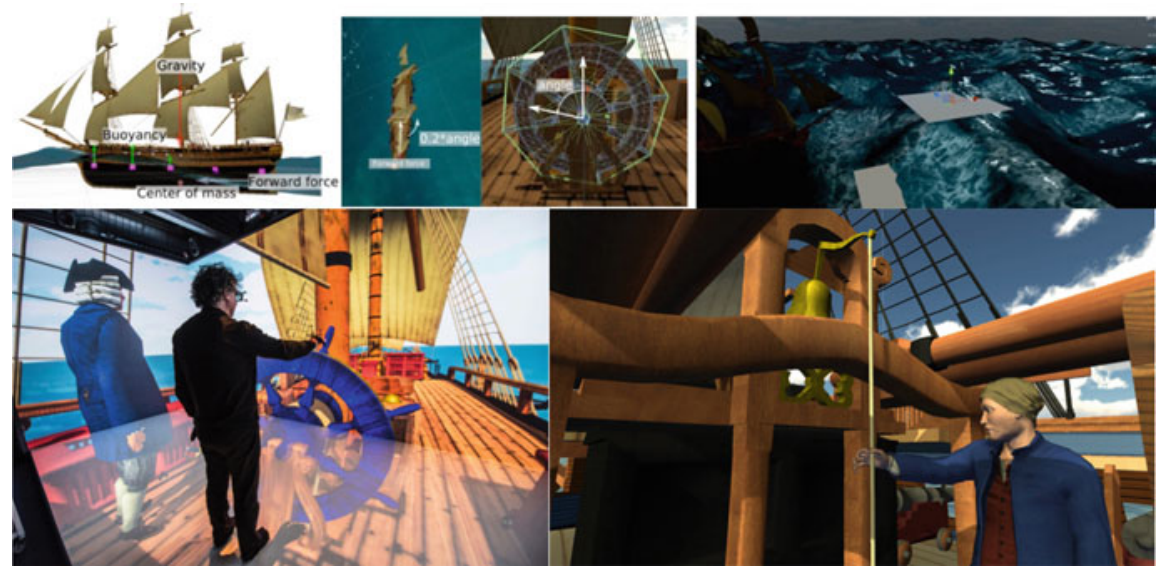

Fig. 48.9 Physical simulation of the Boullongne (top) and functional interactions with the wheel and the bell (bottom)

ship. For example, it is possible to turn the bar of the ship with a physical behavior that transforms the angle of the bar into forces that act on the boat and thus modifies its trajectory. We also added the possibility of ringing a bell or firing a cannon. Figure 48.9 illustrates the physical simulation of the ship and the functional interactions with the wheel and the bell.

\section{Functional Interaction with a Site: Rémire}

The Rémire site is a former sugar plantation run by the Jesuits in the seventeenth and eighteenth centuries in Loyola, French Guiana. For this site, studied by a team of archaeologists from Université Laval in Quebec, we endeavored to simulate its link with the natural environment [84]. The different buildings of the site and its topology were modeled by the West Digital Conservatory for Archaeological Heritage project [83]. Particular attention was paid to the reconstitution of the vegetation of the site, with the modeling of representative trees and plants. We have reconstructed the race of the sun, the moon, and the celestial vault, for a day of the studied time, with the representation of the shades and lighting (Fig. 48.10, center). The user immersed in the environment can change the time scale to easily observe different times of the day (Fig. 48.10, bottom). We also simulated, according to the time of day, the sound environment consisting of animal songs (frogs, birds) by zone according to the plant environment (Fig. 48.10, top, right).

\section{Operational Interactions}

In the following, we present examples of operational interactions implemented in the context of case studies that we have carried out during different projects with archaeologists. Again, these examples are intended to illustrate this case of use of interactions to feed the reflection on its interest in the archaeological operating chains. 

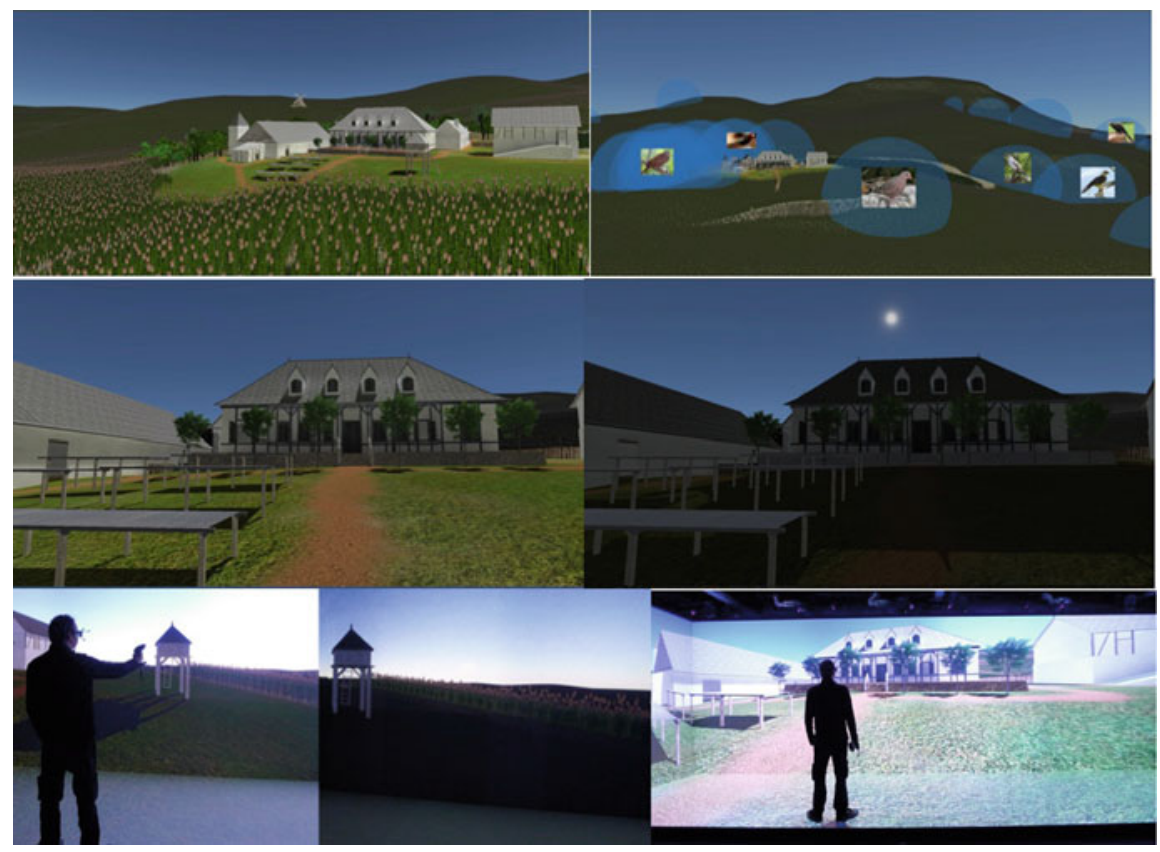

Fig. 48.10 3D model of the site (top, left), sound simulation of the natural environment of the site (top, right), simulation of the night and day course (center), and functional interaction in Virtual Reality (bottom)

\section{Virtual Excavation: The Urn of Guipry}

Archaeological excavation, whether carried out on a site scale or on an archaeological material scale in laboratory (Fig. 48.11, top, left), is a destructive activity for which there is no backtracking or possible replay. Moreover, a search is most often done with no visualization and limited or no knowledge of the underlying content that will be found. Finally, some elements cannot be detected, and their traces are destroyed during the search. We propose augmented and virtual search environments which allow, upstream, to better prepare this real search, in complement, to accompany the real excavation, to document it, or a posteriori, to return on certain elements of the site of excavation. We evaluated in [68] a Mixed Reality system to help preparatory archaeological process (Fig. 48.11, top, right), and we illustrated, in [67], the use of a Virtual Reality tool for the search of a funerary urn of Guipry (in Ille et Vilaine, France). In this example, the user can manipulate, remove the objects from the ballot box, measure them, or annotate them. He can also manipulate cutting plans to visualize the internal structure of the urn. This application, here applied to the Guipry urn, is generic in its design; it can be applied to any 3D model and offer the same features and interactions. The first implementation of the application was deployed on a workbench virtual reality environment (Fig. 48.11, bottom) that was best suited to the size of the archaeological material being studied. 


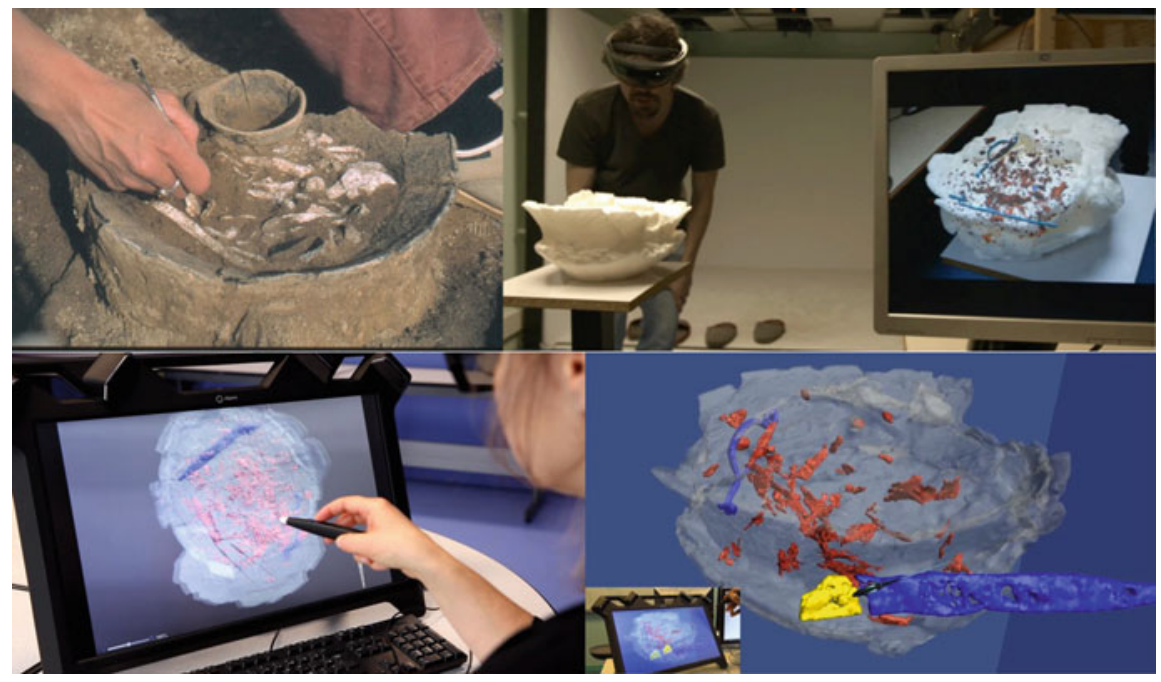

Fig. 48.11 Actual micro-excavation (top, left), Mixed Reality system to visualize inside the urn (top, right), Virtual Reality system to perform virtual excavation (bottom)

\section{Point Cloud Manipulation: The Real Tennis Building of Rennes}

A point cloud is the raw data obtained during laser scanner scanning. This data is generally transformed into a surface mesh to be exploited in $3 \mathrm{D}$. However, the point cloud constitutes in itself 3D data that can be exploited in $\mathrm{XR}$, and which constitutes the most faithful data, the surface generation processes being able to induce errors. This representation is little used so far, because it is complex to implement in an interactive application, especially because it does not benefit from graphic optimization techniques widely developed in computer graphics on the rendering of polygons. We have implemented a number of tools that allow to interact directly with the point cloud, in VR (Fig. 48.12), including an automatic pipeline to transform the PLY point cloud into an octree-structured billboard based on the principle of [85]. For this case study, we are interested in the Real Tennis court of Rennes [86]. The scan of the building generated of point cloud with more than 780 million points. The 3D model generated from the initial point cloud is constituted of more than 500 millions of triangles which is realtime rendered using LOD and occlusion culling optimizations. We offered the user several interactions and tools such as 1:1 navigation, scaling, density change, LOD, measurement, cutting plane, 2D plane, and integration of photo, sketch, and 3D model views [87], as illustrated in Fig. 48.12, bottom. These interactions were designed in collaboration with the archaeologists in charge of the excavation of the building in order to help them in their study: as they had a short time access to the real building, they wanted to be able to come back later into the virtual building, to perform some measurements, to review architectural details, and to document reports. 


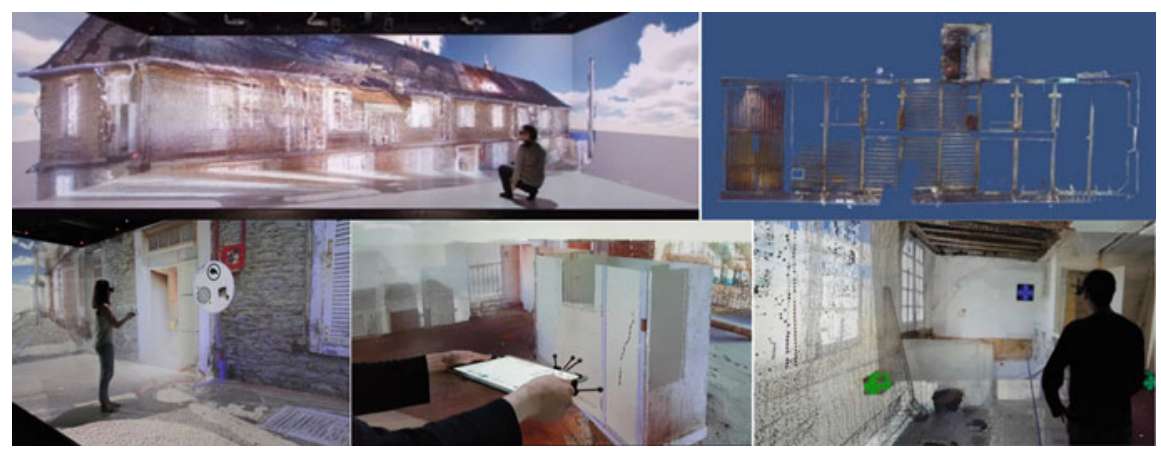

Fig. 48.12 Immersive visualization of the point cloud at 1:1 (top, left), example of 2D cut view obtained with the tool (top, right), interactions with the point cloud in high definition (bottom, left), cutting plan manipulation with a tracked tactile tablet (bottom, center), and position of a photographic view in the Virtual Reality application (bottom, right)

\subsection{Evaluation and Use by Cultural Heritage Experts}

The methodology developed in this chapter aims at proposing new processes and new tools for Cultural Heritage experts. It is thus important to allow these experts that can be archaeologists, historians, or curators, to evaluate them on various use cases. We chose to apply our approach to several actual use cases in order to validate the usefulness of the tools and the efficiency of the processes based on XR applications as presented in Fig. 48.13.

In this section, we detail different use cases and discuss their contribution to Cultural Heritage domain.

\subsubsection{Study of a Cremation Urn}

The cremation urn presented in section "Operational Interactions" was studied following the workflow presented in Fig. 48.14. The urn was digitized using CT scan generating Dicom data. This data was processed using segmentation and 3D surface generation based on radiodensity, in the open source software Horos. This allowed to generate 3D models for the internal content of the urn, especially bones fragments and metal parts.

The segmentation and 3D model generation of a fibula inside the urn was 3D printed and studied by archaeologists before the physical excavation of the urn [88]. The internal content digitization was also used to produce a complex transparent 3D printing of the whole urn and its content [89].

We designed and implemented two XR applications in order to help archaeologists in the study of such material as presented in section "Operational Interactions." 
Fig. 48.13 The evaluation and use of XR applications through use cases

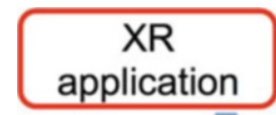

New knowledge \& interpretation

\section{Evaluation / use by $\mathrm{CH}$ experts}
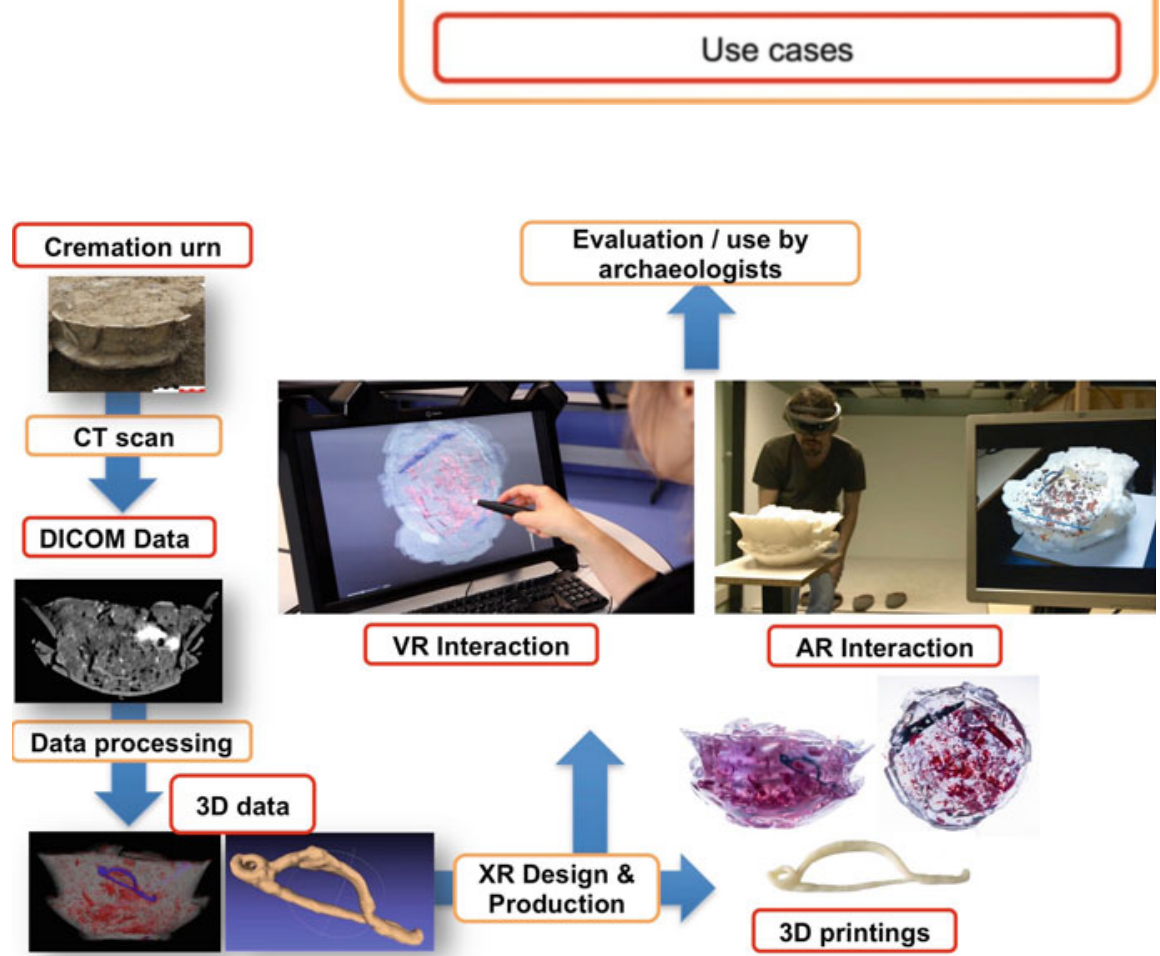

Fig. 48.14 Case study of the cremation urn of Guipry

The digitization process based on CT scan appeared to be very well adapted to the context of such archaeological material. Volume reconstructions from CT scan allow spatial localization of all artifacts and their identification. If modeling indicates how the objects were organized in the burial (in particular the cremated bone), it mainly serves to rapidly determine if the deposits contain sensitive objects such as metal. This information allows to anticipate optimally fine analysis of clusters and to implement protective measures for artifacts. 3D acquisition associated to $3 \mathrm{D}$ printing of particular internal element such as the fibula offers the possibility to duplicate an artifact among others, leading to an immediate typological identification of the artifact, as well as morphological, typometric, or technological observations, regardless of contingencies relative to conservation and restoration operations often required by such objects. This process allows the provision of information within 
hours, which is not the case for the "operational chain" commonly implemented that can take months if protective measures are implemented, prior to the study of the archaeological material.

The complex transparent provides a 3D print of the container and contents (here funeral deposit burned bones and iron objects, knife rivet, and fibula). Its tangible nature allows "direct" access to information and the physical handling of cremation deposit. It allows viewing and manipulation of the vessel and its contents in full and with integrity. Printing allows visualization of burned bones that are imperceptible when excavating (too small, fragile, or appearing negative, to be taken), but also some well-preserved bones (at least here, a long bone) and the determination of iron artifacts (here released from their mineralization). 3D printing also provides information for the reconstruction of the funerary urn. This tangible medium allows a manipulation/simple visualization to work on the analysis (such as the distribution of artifacts and the burial gestures) but also as a support for the excavation. Indeed, 3D printing is the only tangible medium of context pre-served after the excavation of the incineration.

The mixed reality system associates in the same space, the real (cinerary urn) and 3D models obtained from reconstruction. This possibility is perceived by the archaeologist user as a revolution. The system was presented to archaeologists expert in the study of such material. They confirmed the good spatial perception and were able to precisely identify eight different plans of depth, i.e., to differentiate up to eight elements one behind the other, within the urn, to correctly locate the different artifacts, and evaluate the distance between them.

The virtual reality system INSIDE was evaluated by archaeologists to identify the advantages and drawbacks of the method. The virtual introspection interactive tool was confirmed to be really useful to get more information, as the visualization inside the urns shows well the different dispositions of the content, with 3D fragments at the real scale. The identification of fragments was eased by the manipulation of each fragment on its own, to isolate them from the rest. Contrary to the direct visualization of the CT scan, which requires some expertise to get the correct points of view, virtual reality provides natural $3 \mathrm{D}$ interaction such as manipulating a cutting plane. Even though the information displayed is limited by what the scan could give (density and form), it is enough relevant to prepare a real excavation, to concentrate the effort on the regions of interest.

\subsubsection{Reconstitution of an Eighteenth-Century Ship}

The eighteenth-century ship, the Boullongne, introduced in section "Functional Interactions" was reconstituted based on Historical documentary material as presented in Fig. 48.15. Original architectural plans were used to 3D model the ship at 1: 1. The model was integrated in a maritime simulation, with several interactions in order to simulate the functions of the ship. The goal of this work was to enable Historians to be immersed in the subject they were studying and to better understand 


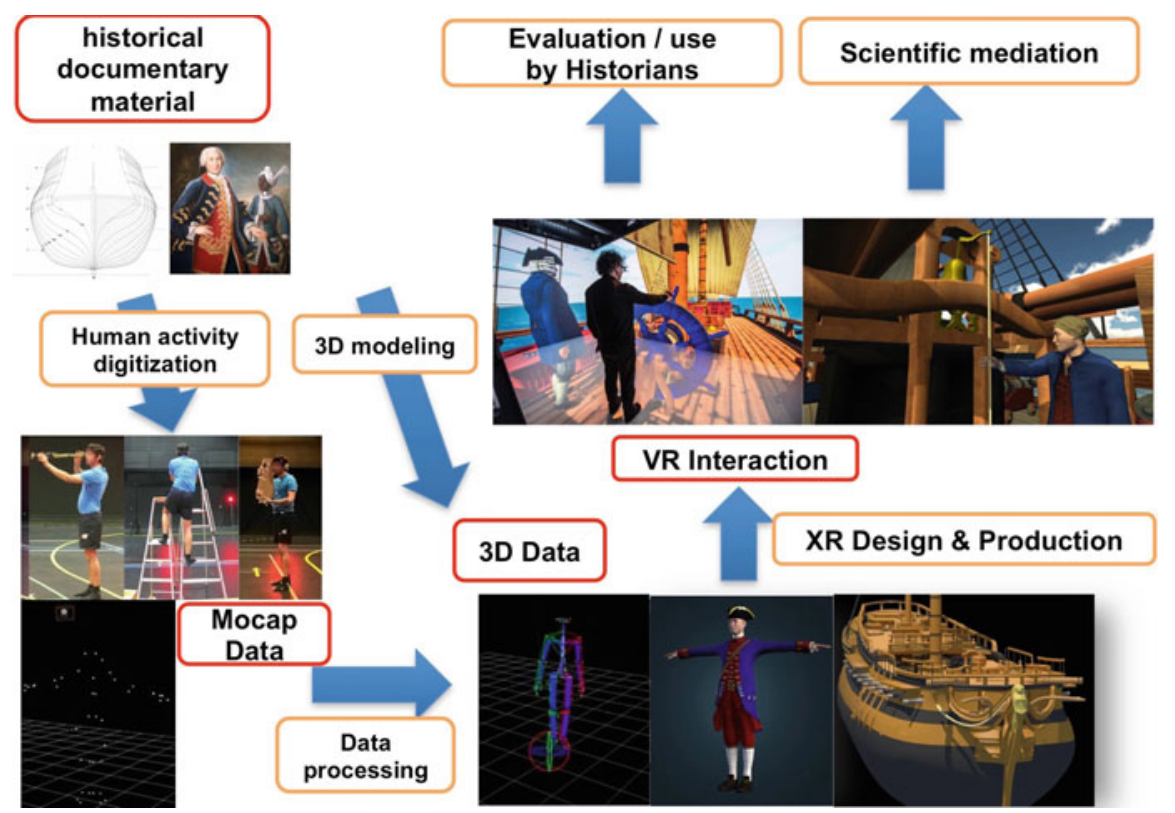

Fig. 48.15 Case study of the eighteenth-century ship, the Boullongne (Source: Musée de la Compagnie des Indes - Ville de Lorient)

the life environment of eighteenth-century sailors in the French East India Company that was testified in archived logbooks of this period.

The virtual reconstitution of La Compagnie des Indes Orientales ship allows a new practice of validation of the historical sources in an innovative application environment, involving historians' own physical activities and their perceptions. Being positioned on a ship in scale-one enables maritime historians to appreciate living and working conditions in a small space, overpopulated and in perpetual movement.

The historical reconstitution of Le Boullongne allows historians to understand the architecture of a merchant ship and especially to assess the dimensions and volumes of the different spaces, from the hold to the deck.

Historians try to figure out how life could be organized on the ship during trips that lasted between 5 and 6 months, with maximum congestion and strong promiscuity, as the ship carried between 130 and 150 persons. For example, the transition from forward to stern on the upper deck, or the height of the steerage where the guns are placed, seemed extremely narrow to historians. This raises the question of the actual use of guns, and the concrete movement of sailors and passengers on the upper deck. All these thoughts and discussions between historians were aroused following the natural 1:1 exploration of the ship. In particular, the necessity of walking in a crouching stance in the intermediate decks evoked in Historians a study of historical archives of La Compagnie des Indes Orientales which highlighted a particular 
pathology for sailors: most of them suffered a hernia. Carrying and storing goods in the confined cargo holds, with no possibility of standing up, may partly explain this pathology.

A specific work dedicated to the study of human activities in the ship used motion capture and graphical design of Historically consistent characters to reconstitute some life scenes. The real activities were designed and played by Historians, and recorded with a Mocap optical system. The scenes were integrated as triggered animations inside the VR application [90]. In this particular work, instead of usual objects or monuments, a particular human activity is digitized, relying on intangible heritage.

Such simulation allows historians to sail on a disappeared ship. It enables a better understanding of how on-board life was organized, providing an immersive selfexperience of the behavior of the ship. It also constitutes a powerful pedagogical tool, giving life to a valuable testimony of our history. The virtual sailing was presented to several public exhibitions.

\subsubsection{Process of Analysis of a Gallic Grave}

In the context of a preventive archaeological investigation, an exceptional aristocratic Gallic grave at Warcq was discovered and excavated by Inrap. The remains discovered in the grave have revealed to be exceptional. The vast funerary chamber $(5.50 \times 2.80 \mathrm{~m})$ was preserved to a depth of more than a meter. In this damp environment, the wooden walls and ceiling were extremely well preserved. Over time, the latter had collapsed directly onto the floor of the chamber, covering the deceased and his goods. The funerary artifacts discovered were of unusually high quality. The main item was a two-wheeled ceremonial chariot. One of the most spectacular elements was the burial of four horses around the vehicle. The deceased person, most likely a man, was lying on the body of the chariot.

As the ground environment of the excavation in Warcq was very wet, it was decided to sample complete blocks in the grave around some pieces of interest that required a cautious excavation process [91]. Seven blocks were scanned in order to prepare their micro-excavation and restoration. The block S1 contains the wheel hub, the blocks S2 and S3 contain two buckets, the block S4 contains the rim of one wheel, the blocks S5 and S6 contain the harnessed heads of the two horses ahead the chariot (Fig. 48.5), and the block S7 contains a yoke.

The data generated during the $\mathrm{CT}$ scan was processed in order to perform preliminary studies and segmentation and generate volume rendering and surface rendering. CT scan data (sections, 3D reconstruction) guided all stages of microexcavation. These operations were carried out in collaboration between the archaeologist and the curator. The whole process of micro digging has also been documented using photogrammetry. All the samples followed the same process: the micro-search, guided by CT data, under a magnifying glass, is followed by a cleaning for the study by micro-sandblasting under a binocular loupe. 
This process has been particularly efficient for the study of two harnessed horse heads where it has allowed the researchers to observe, quantify, and locate the presence of objects inside the samples upstream of the intervention, despite the poor state of conservation. The information was very useful to assist the restorer during micro-excavation. The most important example is the decoration of the harness. These visible elements on the images from the CT scan are very small. They were composed of very thin sheet of copper alloy originally covering the nail heads. They were not all found during the micro digging because of their size, the very complex sediment to search through, and their state of conservation. Imaging and direct observations on the micro frame made it possible to restore the different elements of the harness (Fig. 48.16).

We used 3D surface rendering to generate 3D meshes corresponding to different density ranges in order to produce a 3D print that highlights the spatial organization of the metal parts of the harness. We chose to use a technique of transparent printing of the block, with different colors for the internal elements. The transparent 3D printing constitutes a tangible spatial recording of the horse head, with the nails visible; it offers a better visualization and perception of the volume of spatialization and of the relation between the objects. The head itself was not restorable aside from the teeth, as there is no more bone matter. 3D printing has thus a long-term goal of safeguarding.

The digital data of the different samples were integrated in a full restitution of several steps of the excavation of the complete grave, in virtual reality. Both photogrammetric and CT data of samples were integrated in the reconstitution and manipulable by the user with the possibility to switch between the different views. Several tools of operational interactions such as measurement, magnification, and

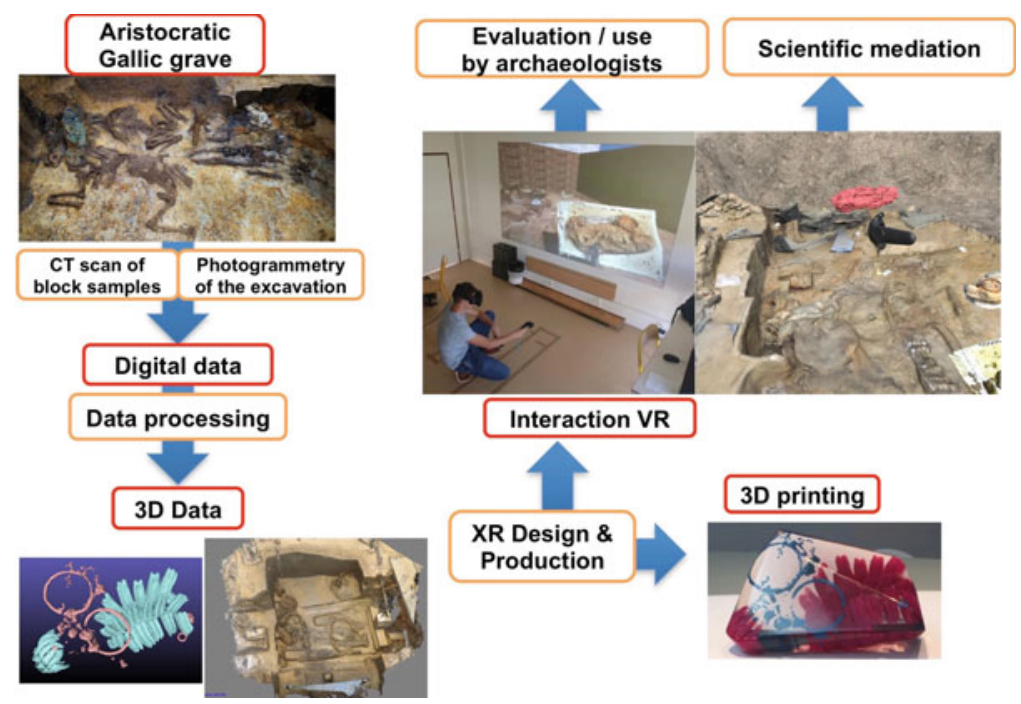

Fig. 48.16 Case study of the aristocratic Gallic grave of Warcq 
X Rays view of the objects are proposed to the user. Archaeologists in charge of the excavation tried the virtual reconstitution. The first comment was that they never had a complete view of the grave during the excavation because of the presence of scaffolding. This complete view gave them a new perspective of the organization of the grave.

In this work, computed tomography and 3D printing are tools within an "operating chain" of analysis that involves the interaction of different experts. Virtual reality provides different views of the site, with the access to different steps of the excavation and a complete overview of the grave. These views were impossible in the actual grave; they open new perspectives to apprehend a site and its excavation process.

\subsubsection{Annotation of Megalithic Art with Augmented Reality}

Megalithic art is a spectacular form of symbolic representation found on prehistoric monuments. Carved by Europe's first farmers, this type of art allows an insight into the creativity and vision of prehistoric communities. As examples of this art continue to fade, it is increasingly important to document and study these symbols. In [14] we introduced MAAP Annotate, a Mixed Reality annotation tool developed as part of a project (the Megalithic Art Analysis Project - MAAP) with the school of Archaeology of the University College Dublin (UCD), Ireland. It provides an innovative method of interacting with megalithic art, combining cross-disciplinary research in digital heritage, 3D scanning and imaging, as well as Augmented Reality (AR); see Fig. 48.17.

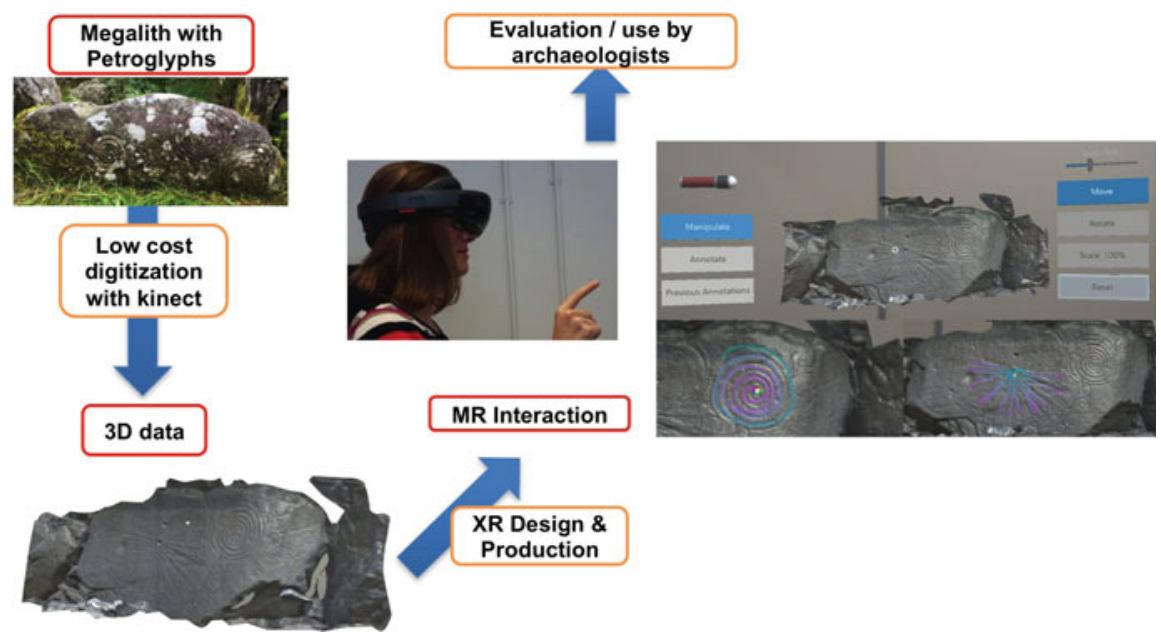

Fig. 48.17 Megalithic Art annotation with Augmented Reality 
We put a particular attention in the scanning process, with a portable autonomous system based on the use of a laptop and a Microsoft Kinect to offer archaeologists the possibility to scan in real-time the art directly onsite (i.e., in an outdoor environment).

Once the art was scanned and a 3D model was obtained, we focused on the development of an AR annotation tool for megalithic art. It was designed to be used by archaeologists and not by computer scientists as a unique mean to examine megalithic art offsite. Indeed, one of the issues with megalithic art consists of being able to determine what is really art and what is only due to the natural erosion of the stones.

MAAP Annotate was thus designed with input from archaeologists who had no prior experience with Mixed Reality devices in order to provide them with the tools they need in achieving this distinction between art and erosion. We thus offered them the possibility to manipulate the scanned 3D stones (i.e., to change their scale, to rotate them, etc.) as well as natural selection tools to identify art on the stones and more user-specific tools such as a virtual flashlight that is used to cast shadows on the 3D stone to better detect shallow engravings.

An evaluation of the resulting tool was carried out on a group of 10 experts (archaeologists from UCD's school of Archaeology), using an optical see-through HMD. The test confirmed that this application is usable and that archaeologists view the use of Augmented Reality as an excellent way to annotate megalithic art.

One interesting feedback about this tool is the possibility of being able to view a stone and take notes simultaneously without being interrupted by the necessity to write on paper. This characteristic of systems based on a Mixed Reality HMD device was also pointed out and appreciated in the tool presented in Sect. 48.6.1.

\subsection{Conclusion}

Methods and tools for Cultural Heritage based on eXtended Reality open new perspectives and research questions but also new ways of understanding the professions of Cultural Heritage practitioners.

Interactions with digital objects in eXtended Reality allow Cultural Heritage experts to work in a non-destructive way on archaeological or historical material that is generally extremely fragile, often difficult to access, and sometimes not visible to the naked eye.

$3 \mathrm{D}$ interaction tools provide support to the excavation or restoration operations for the archaeologist. For example, it is possible to prepare an upstream operation, or guide it during its realization. In this case, the proposed interactions are said to be operational. In addition, 3D data can be integrated into a richer virtual world that allows one to contextualize the artifact, be it a context of manufacture, use, or discovery. In this case, it is possible to propose interactions with a simulation of the function of the artifact. In this case, the proposed interactions are said to be functional. These tools have shown to also provide support to historians by allowing them to be immersed in historical contexts that no more exist. 
This research also represents new scientific challenges in the realm of virtual, augmented, or mixed realities. The perception of 3D universes through the specificity of the archaeologist as a user is a very promising area. As a professional expert, the Cultural Heritage expert does not necessarily look for a photorealistic representation of his study space, like the doctor who studies his patient through an X-ray or MRI. The scale-1 interaction with physical displacement is in itself an interesting 3D digital world approach in archaeology and more generally Cultural Heritage, as it combines a mode of perception, proprioception, and a fundamental interaction, natural navigation, which are not accessible through a simple screen keyboardmouse. Interactions with multi-scale areal or surface objects represent challenges that remain to be overcome and that will allow access to data of great richness. The interaction with tangible objects in mixed reality opens an important field of investigation, especially for interpretation in multiple contexts.

Finally, the Cultural Heritage expert can dynamically interact on several levels: he seeks the links between the elements of a site, his own interactions with these elements, but also the interactions that could have humans at the time with this site. It is therefore also important to propose representations and simulations of human activity in contextualized environments.

\section{References}

1. Milgram P, Kishino F (1994) A taxonomy of mixed reality visual displays. IEICE Trans Inf Syst E77-D(12):1321-1329

2. Fuchs P, Moreau G, Guitton P (2011) Virtual reality: concepts and technologies, 1st edn. CRC Press, Boca Raton

3. Pimentel K, Teixeira K, Jamet D (1994) La réalité virtuelle...: de l'autre côté du miroir. Ed. Addison-Wesley

4. Azuma RT, Baillot Y, Behringer R, Feiner S, Julier S, MacIntyre B (2001) Recent advances in augmented reality. IEEE Comput Graph Appl 21(6):34-47

5. Reilly P (1990) Towards a virtual archaeology. In: Computer applications in archaeology. British Archaeological Reports, Oxford, pp 133-139

6. Krasniewicz L (2000) Immersive imaging technologies for archaeological research. In: CAA: the 28th conference on computer applications and quantitative methods in archaeology, vol 843, pp 163-169

7. Pujol-Tost L (2011) Realism in virtual reality applications for Cultural Heritage. Int J Virtual Real 10(3):41

8. Forte M (2011) Cyber-archaeology: notes on the simulation of the past. Virtual Archaeol Rev 2(4):7-18

9. Christou C, Angus C, Loscos C, Dettori A, Roussou M (2006) A versatile large-scale multimodal VR system for Cultural Heritage visualization. In: Proceedings of the ACM symposium on virtual reality software and technology, VRST '06. ACM, New York, pp 133-140

10. Vote E, Feliz DA, Laidlaw DH, Joukowsky MS (2002) Discovering Petra: archaeological analysis in VR. IEEE Comput Graph Appl 22(5):38-50; Acevedo D, Vote E, Laidlaw D, Joukowsky M (2001) Archaeological data visualization in VR: analysis of lamp finds at the Great Temple of Petra, a case study. https://doi.org/10.1109/VISUAL.2001.964560

11. Forte M, Kurillo G (2010) Cyberarchaeology: experimenting with teleimmersive archaeology. In: 2010 16th international conference on virtual systems and multimedia, pp 155-162 
12. Nicolas T, Gaugne R, Tavernier C, Petit Q, Gouranton V, Arnaldi B (2015) Touching and interacting with inaccessible Cultural Heritage. Presence Teleop Virt 24(3):265-277

13. Lim C-K, Cani M-P, Galvane Q, Pettré J, Zawawi TA (2013) Simulation of past life: controlling agent behaviors from the interactions between ethnic groups. In: 2013 digital heritage international congress (DigitalHeritage), vol 1, pp 589-596

14. Barbier J, Kenny P, Young J, Normand J-M, Keane MT, O’Sullivan M, Ventresque A (2017) MAAP annotate: when archaeology meets augmented reality for annotation of megalithic art. In: 23rd international conference on virtual system \& multimedia, VSMM 2017, pp 1-8

15. Hermon S, Nikodem J 3D Modelling as a scientific research tool in archaeology. In: Posluschny A, Lambers K, Herzog I (eds) Proceedings of the 35th international conference on computer applications and quantitative methods in archaeology, Apr 2007, pp 140-145 + CD-ROM

16. Slama CC (1980) Manual of photogrammetry. Technical report, America Society of Photogrammetry

17. Ullman S (1979) The interpretation of structure from motion. Proc R Soc Lond B 203(1153): $405-426$

18. Aicardi I, Chiabrando F, Lingua AM, Noardo F (2018) Recent trends in Cultural Heritage 3D survey: the photogrammetric computer vision approach. J Cult Herit 32:257-266

19. Dhanda A, Reina Ortiz M, Weigert A, Paladini A, Min A, Gyi M, Su S, Fai S, Santana Quintero M (2019) Recreating Cultural Heritage environments for VR using photogrammetry. Int Arch Photogramm Remote Sens Spatial Inf Sci XLII-2/W9:305-310. https://doi.org/10.5194/isprsarchives-XLII-2-W9-305-2019

20. Anderson EF, John D, Mikulski R, Redford A, Romero M (2020) Preserving and presenting Cultural Heritage using off-the-shelf software. In: Visual computing for Cultural Heritage. Springer, pp 423-444

21. Pierdicca R, Frontoni E, Malinverni ES, Colosi F, Orazi R (2016) Virtual reconstruction of archaeological heritage using a combination of photogrammetric techniques: Huaca Arco Iris, Chan Chan, Peru. Digital Appl Archaeol Cult Herit 3(3):80-90

22. Quattrini R, Nespeca R, Ruggeri L (2017) Digital photogrammetry for archaeological artefacts acquisition. In: IMEKO international conference on metrology for archaeology and Cultural Heritage, pp 643-648

23. Smisek J, Jancosek M, Pajdla T (2013) 3D with kinect. In: Consumer depth cameras for computer vision. Springer, pp 3-25

24. Cappelletto E, Zanuttigh P, Cortelazzo GM (2016) 3d scanning of Cultural Heritage with consumer depth cameras. Multimed Tools Appl 75(7):3631-3654

25. Allegra D, Gallo G, Inzerillo L, Lombardo M, Milotta FLM, Santagati C, Stanco F (2016) Low cost handheld $3 \mathrm{~d}$ scanning for architectural elements acquisition. In: Eurographics Italian chapter conference, pp 127-131.

26. Mancini F, Dubbini M, Gattelli M, Stecchi F, Fabbri S, Gabbianelli G (2013) Using unmanned aerial vehicles (UAV) for high-resolution reconstruction of topography: the structure from motion approach on coastal environments. Remote Sens 5(12):6880-6898

27. Jo YH, Hong S (2019) Three-dimensional digital documentation of Cultural Heritage site based on the convergence of terrestrial laser scanning and unmanned aerial vehicle photogrammetry. ISPRS Int J Geo Inf 8(2):53

28. Themistocleous K, Mettas C, Evagorou E, Hadjimitsis D (2019) The use of UAVs and photogrammetry for the documentation of Cultural Heritage monuments: the case study of the churches in Cyprus. In: Earth resources and environmental remote sensing/GIS applications X, vol 11156. International Society for Optics and Photonics, p 111560I

29. Mudge M, Malzbender T, Schroer C, Lum M (2006) New reflection transformation imaging methods for rock art and multiple-viewpoint display. In: VAST, vol 6, pp 195-202. Citeseer

30. Wei W, Huang L, Zhu X, Ling L, Guo K, Huang H (2019) Application of reflectance transformation imaging for the display of handwriting traces. Chin Opt Lett 17(11):111101

31. Saunders D, Collmann R, Siddall L (2016) Reflectance transformation imaging and the cuneiform in Australia and New Zealand collections project. Buried History 52:45-48 
32. Gaugne R, Labaune F, Fontaine D, Le Cloirec G, Gouranton V (2020) From the engraved tablet to the digital tablet, history of a fifteenth century music score. ACM J Comput Cult Herit, to appear 17:1-18. https://doi.org/10.1145/3383782

33. Boehler W, Heinz G, Marbs A (2002) The potential of noncontact close range laser scanners for Cultural Heritage recording. Int Arch Photogramm Remote Sens Spat Inf Sci 34(5/C7):430-436

34. Kushwaha SKP, Dayal KR, Raghavendra S, Pande H, Tiwari PS, Agrawal S, Srivastava SK et al (2020) 3D digital documentation of a Cultural Heritage site using terrestrial laser scanner - a case study. In: Applications of geomatics in civil engineering. Springer, pp 49-58

35. Quagliarini E, Clini P, Ripanti M (2017) Fast, low cost and safe methodology for the assessment of the state of conservation of historical buildings from 3D laser scanning: the case study of Santa Maria in Portonovo (Italy). J Cult Herit 24:175-183

36. Fantoni R, Almaviva S, Caneve L, Caponero M, Colao F, Ferri De Collibus M, Fiorani L, Fornetti G, Francucci M, Guarneri M et al (2017) Laser scanners for remote diagnostic and virtual fruition of Cultural Heritage. Opt Quant Electron 49(3):120

37. Lezzerini M, Antonelli F, Columbu S, Gadducci R, Marradi A, Miriello D, Parodi L, Secchiari L, Lazzeri A (2016) Cultural Heritage documentation and conservation: threedimensional (3D) laser scanning and geographical information system (GIS) techniques for thematic mapping of facade stonework of St. Nicholas Church (Pisa, Italy). Int J Archit Herit 10(1):9-19

38. Lachat E, Landes T, Grussenmeyer P (2017) Performance investigation of a handheld 3D scanner to define good practices for small artefact 3D modeling. Int Arch Photogramm Remote Sens Spat Inf Sci XLII-2/W5:427-434. https://doi.org/10.5194/isprs-archives-XLII-2-W5-4272017

39. Applbaum N, Applbaum YH (2005) The use of medical computed tomography (CT) imaging in the study of ceramic and clay archaeological artifacts from the ancient near east. In: X-rays for archaeology. Springer, pp 231-245

40. Re A, Giudice AL, Nervo M, Buscaglia P, Luciani P, Borla M, Greco C (2016) The importance of tomography studying wooden artefacts: a comparison with radiography in the case of a coffin lid from ancient Egypt. Int J Con Sci 7(2):935-944

41. Kobayashi K, Hwang S-W, Okochi T, Lee W-H, Sugiyama J (2019) Non-destructive method for wood identification using conventional x-ray computed tomography data. J Cult Herit 38:88-93

42. Wilson P, Williams MA, Warnett JM, Attridge A, Ketchum H, Hay J, Smith MP (2017) Utilizing X-ray computed tomography for heritage conservation: the case of Megalosaurus bucklandii. In: 2017 IEEE international instrumentation and measurement technology conference (I2MTC). IEEE, pp 1-5

43. Murphy C, Fuller DQ, Stevens C, Gregory T, Parracho Silva F, Dal Martello R, Song J, Bodey AJ, Rau C (2019) Looking beyond the surface: use of high resolution x-ray computed tomography on archaeobotanical remains. Interdiscip Archaeol 10(1):7-18. https://doi.org/10.24916/ iansa.2019.1.1

44. Kirsch S (2019) Computed tomography as a tool for archiving ethnomusicological objects. In: Computational phonogram archiving. Springer, pp 305-319

45. Herman GT (2009) Fundamentals of computerized tomography: image reconstruction from projection. Springer

46. Edholm P, Herman G (1987) Linograms in image reconstruction from projections. Trans Med Imaging 6(4):301-307. https://doi.org/10.1109/TMI.1987.4307847

47. Hounsfield GN (1973) Computerized transverse axial scanning (tomography): part 1. Description of system. Br J Radiol 46(552):1016-1022

48. Vergnieux R (2011) Archaeological research and 3d models (restitution, validation and simulation). Virtual Archaeol Rev 2(4):39-43

49. Madrazo L (1994) Durand and the science of architecture. J Archit Educ 48(1):12-24

50. Palermo PC, Ponzini D (2010) Spatial planning and urban development: critical perspectives, vol 10. Springer Science \& Business Media 
51. Gonizzi Barsanti S, Remondino F, Visintini D (2012) Photogrammetry and laser scanning for archaeological site 3D modeling-some critical issues. In: Roberto V, Fozzati L (eds) Proceedings of the 2nd workshop on 'the new technologies for Aquileia'. http://ceur-ws.org/Vol948/

52. Stewart Z (2018) Tending the architectural corpus: a prehistory. J Archit Educ 72(2):290-293

53. Bressani, M. (2014). Architecture and the Historical Imagination: Eugène-Emmanuel Violletle-Duc, 1814-1879 (1st ed.). Routledge. https://doi.org/10.4324/9781315567679

54. Fuchs A (2006) Outils numériques pour le relevé architectural et la restitution archéologique. Theses, Université Henri Poincaré - Nancy I

55. Bennoui-Ladraa B, Chennaoui Y (2018) Use of photogrammetry for digital surveying, documentation and communication of the Cultural Heritage. example regarding virtual reconstruction of the access doors for the nameless temple of tipasa (algeria). Stud Digital Herit 2(2):121-137

56. Dawn S, Biswas P (2018) Technologies and methods for 3d reconstruction in archaeology. In: International symposium on signal processing and intelligent recognition systems. Springer, pp 443-453

57. Santacana i Mestre J, Carme Belarte Franco M (2005) Idées et débats de la restitution en archéologie, problèmes généraux concernant la restitution en archéologie. Centre des Monuments Nationaux, Editions du Patrimoine, pp 6-10

58. Gosselin LP (2014) Analyse des processus de recherche et de modélisation du patrimoine à partir de deux cas: l'écluse saint-gabriel du canal de lachine et la gare montreal and southern counties railways co. Masters' thesis, Université de Sherbrooke

59. Huggett J (2015) A manifesto for an introspective digital archaeology. Open Archaeol 1(1): $86-95$

60. Bekele MK, Pierdicca R, Frontoni E, Malinverni ES, Gain J (2018) A survey of augmented, virtual, and mixed reality for Cultural Heritage. J Comput Cult Herit 11(2):1-36. https://doi.org/ $10.1145 / 3145534$

61. Carrozzino M, Voinea G-D, Duguleană M, Boboc RG, Bergamasco M (2019) Comparing innovative XR systems in Cultural Heritage. A case study. Int Arch Photogramm Remote Sens Spat Inf Sci XLII-2/W11:373-378. https://doi.org/10.5194/isprs-archives-XLII-2-W11373-2019

62. Ch'ng E, Li Y, Cai S, Leow F-T (2020) The effects of vr environments on the acceptance, experience, and expectations of Cultural Heritage learning. J Comput Cult Herit (JOCCH) 13(1): $1-21$

63. Cruz-Neira C, Sandin DJ, DeFanti TA, Kenyon RV, Hart JC (1992) The cave: audio visual experience automatic virtual environment. Commun ACM 35(6):64-72

64. Gaugne R, Gouranton V, Dumont G, Chauffaut A, Arnaldi B (2014) Immersia, an open immersive infrastructure: doing archaeology in virtual reality. Archeologia e Calcolatori, supplemento 5:1-10

65. Katsouri I, Tzanavari A, Herakleous K, Poullis C (2015) Visualizing and assessing hypotheses for marine archaeology in a VR CAVE environment. J Comput Cult Herit 8(2):1-18. https://doi. org $/ 10.1145 / 2665072$

66. Skarlatos D, Agrafiotis P, Balogh T, Bruno F, Castro F, Petriaggi BD, Demesticha S, Doulamis A, Drap P, Georgopoulos A, Kikillos F, Kyriakidis P, Liarokapis F, Poullis C, Rizvic S (2016) Project imareculture: advanced VR, immersive serious games and augmented reality as tools to raise awareness and access to European underwater Cultural Heritage. In: Ioannides M, Fink E, Moropoulou A, Hagedorn-Saupe M, Fresa A, Liestøl G, Rajcic V, Grussenmeyer P (eds) Digital heritage. Progress in Cultural Heritage: documentation, preservation, and protection. Springer International Publishing, Cham, pp 805-813

67. Lécuyer F, Gouranton V, Gaugne R, Nicolas T, Marchand G, Arnaldi B INSIDE interactive and non-destructive solution for introspection in digital environments. In: Digital heritage 2018 3rd international congress \& expo, IEEE, new realities: authenticity \& automation in the digital age, San Francisco, United States, October 2018, pp 1-4 
68. Gaugne R, Petit Q, Nicolas T, Otsuki M, Gouranton V (2019) Evaluation of a mixed reality based method for archaeological excavation support. In: ICAT-EGVE: international conference on artificial reality and telexistence \& Eurographics symposium on virtual environments, 2019, pp 1-8

69. Bimber O, Raskar R (2005) Spatial augmented reality: merging real and virtual worlds. A K Peters/CRC Press

70. Kurth P, Lange V, Siegl C, Stamminger M, Bauer F (2018) Auto-calibration for dynamic multiprojection mapping on arbitrary surfaces. IEEE Trans Vis Comput Graph 24(11):2886-2894. https://doi.org/10.1109/TVCG.2018.2868530

71. Ridel B, Reuter P, Laviole J, Mellado N, Couture N, Granier X (2014) The revealing flashlight: interactive spatial augmented reality for detail exploration of Cultural Heritage artifacts. J Comput Cult Herit 7(2):6:1-6:18

72. Gaugne R, Porcier S, Nicolas T, Coulon F, Hays O, Gouranton V A digital introspection of a mummy cat. In: Digital heritage, 3rd international congress \& expo, new realities: authenticity $\&$ automation in the digital age, IEEE, San Francisco, 2018, pp 1-8

73. Bowman DA, Johnson DB, Hodges LF (1999) Testbed evaluation of virtual environment interaction techniques. In: Proceedings of the ACM symposium on virtual reality software and technology, VRST'99. ACM, New York, pp 26-33

74. Hain V, Hajtmanek R (2019) Industrial heritage education and user tracking in virtual reality. In: Virtual reality. IntechOpen

75. Barreau J-B, Nouviale F, Gaugne R, Bernard Y, Llinares S, Gouranton V (2015) An immersive virtual sailing on the 18th-century ship Le Boullongne. Presence Teleop Virt Environ 24(3):201-219. https://doi.org/10.1162/PRES_a_00231

76. Chheang V, Saalfeld P, Huber T, Huettl F, Kneist W, Preim B, Hansen C (2019) Collaborative virtual reality for laparoscopic liver surgery training. In: IEEE international conference on artificial intelligence and virtual reality (AIVR)

77. Monsky WL, James R, Seslar SS (2019) Virtual and augmented reality applications in medicine and surgery-the fantastic voyage is here. Anat Physiol 9(1):313

78. Claude G, Gouranton V, Caillaud B, Gibaud B, Arnaldi B, Jannin P (2016) Synthesis and simulation of surgical process models. Stud Health Technol Inform 220:63-70

79. Roldán JJ, Crespo E, Martín-Barrio A, Peña-Tapia E, Barrientos A (2019) A training system for industry 4.0 operators in complex assemblies based on virtual reality and process mining. Robot Comput Integr Manuf 59:305-316

80. Santamaría-Bonfil G, Ibáñez MB, Pérez-Ramírez M, Arroyo-Figueroa G, Martínez-Álvarez F (2020) Learning analytics for student modeling in virtual reality training systems: lineworkers case. Comput Educ 151. https://doi.org/10.1016/j.compedu.2020.103871

81. R. B. Berthelot, T. Lopez, F. Nouviale, V. Gouranton, B. Arnaldi. Corvette: collaborative environment for technical training and experiment. In: 2014 IEEE virtual reality (VR), March 2014, pp 145-145

82. Cousseau F, Bernard Y, Petit Q, Barreau J-B, Gaugne R, Quesnel L Relever les élévations d'une architecture mégalithique: développements méthodologiques. In: GMPCA 2017 - XXIème Colloque international du Groupe des Méthodes Pluridisciplinaires Contribuant à l'Archéologie, Rennes, France, April 2017. CNRS UMR6566 CReAAH

83. Barreau J-B, Gaugne R, Bernard Y, Le Cloirec G, Gouranton V (2013) The west digital conservatory of archaelogical heritage project. In: DH, France, 2013, pp 1-8

84. Barreau J-B, Petit Q, Bernard Y, Auger R, Le Roux Y, Gaugne R, Gouranton V 3D reconstitution of the Loyola sugar plantation and virtual reality applications. In: Proceedings of computer applications \& quantitative methods in archaeology, CAA, Sienna, Italy, 2015

85. Kreylos O, Bawden GW, Kellogg LH (2008) Immersive visualization and analysis of lidar data. In: International symposium on visual computing. Springer, pp 846-855

86. Barreau J-B, Gaugne R, Gouranton V (2017) Immersive point cloud manipulation for Cultural Heritage documentation. ERCIM News:33-34

87. Gaugne R, Petit Q, Barreau J-B, Gouranton V (2019) Interactive and immersive tools for point clouds in archaeology. In: ICAT-EGVE: international conference on artificial reality and telexistence \& Eurographics symposium on virtual environments, 2019, pp 1-8 
88. Nicolas T, Gaugne R, Tavernier C, Gouranton V, Arnaldi B (2014) Preservative approach to study encased archaeological artefacts. In: Ioannides M, Magnenat-Thalmann N, Fink E, Žarnić R, Yen A-Y, Quak E (eds) Digital heritage. progress in Cultural Heritage: documentation, preservation, and protection: 5th international conference, EuroMed 2014, Limassol, Cyprus, November 3-8, 2014. Proceedings. Springer International Publishing, Cham, pp 332-341

89. Nicolas T, Gaugne R, Tavernier C, Gouranton V, Arnaldi B (2016) Internal 3D printing of intricate structures. In: Ioannides M, Fink E, Moropoulou A, Hagedorn-Saupe M, Fresa A, Liestøl G, Rajcic V, Grussenmeyer P (eds) 6th international conference on culturage heritage EuroMed 2016, volume 10058 of Lecture notes in computer science, Nicosia, Cyprus, October 2016, pp 432-441

90. Barreau J-B, Gaugne R, Olivier A-H, Llinares S, Gouranton V (2019) Reconstitution de la vie à bord d'un navire de la Compagnie des Indes Orientales au 18e siècle. In Situ: Revue des Patrimoines 39(2)

91. Nicolas T, Gaugne R, Tavernier C, Millet E, Bernadet R, Gouranton V (2018) Lift the veil of the block samples from the Warcq chariot burial with 3D digital technologies. In: Digital heritage 2018, 3rd international congress \& expo, new realities: authenticity \& automation in the digital age, San Francisco. IEEE, pp 1-8. https://doi.org/10.1109/DigitalHeritage.2018.8810036 